\title{
Mechanisms Underlying Enhancement of Spontaneous Glutamate Release by Group I mGluRs at a Central Auditory Synapse
}

\author{
Kang Peng, ${ }^{1}{ }^{\oplus}$ Xiaoyu Wang, ${ }^{2}{ }^{\oplus}$ Yuan Wang, ${ }^{2}$ Dainan Li, ${ }^{3}{ }^{\oplus}$ Hai Huang, ${ }^{3}$ and ${ }^{\oplus}$ Yong Lu ${ }^{1}$ \\ ${ }^{1}$ Department of Anatomy and Neurobiology, Hearing Research Group, College of Medicine, Northeast Ohio Medical University, Rootstown, Ohio \\ 44272, ${ }^{2}$ Department of Biomedical Science, Program in Neuroscience, Florida State University College of Medicine, Tallahassee, Florida 32306, and \\ ${ }^{3}$ Department of Cell and Molecular Biology, Brain Institute, Tulane University, New Orleans, Louisiana 70118
}

One emerging concept in neuroscience states that synaptic vesicles and the molecular machinery underlying spontaneous transmitter release are different from those underlying action potential-driven synchronized transmitter release. Differential neuromodulation of these two distinct release modes by metabotropic glutamate receptors (mGluRs) constitutes critical supporting evidence. However, the mechanisms underlying such a differential modulation are not understood. Here, we investigated the mechanisms of the modulation by group I mGluRs (mGluR Is) on spontaneous glutamate release in the medial nucleus of the trapezoid body (MNTB), an auditory brainstem nucleus critically involved in sound localization. Whole-cell patch recordings from brainstem slices of mice of both sexes were performed. Activation of mGluR I by 3,5-dihydroxyphenylglycine (3,5-DHPG; $200 \mu \mathrm{M})$ produced an inward current at $-60 \mathrm{mV}$ and increased spontaneous glutamate release in MNTB neurons. Pharmacological evidence indicated involvement of both mGluR1 and mGluR5, which was further supported for mGluR5 by immunolabeling results. The modulation was eliminated by blocking $\mathrm{Na}_{\mathrm{V}}$ channels (tetrodotoxin, $1 \mu \mathrm{M}$ ), persistent $\mathrm{Na}^{+}$current $\left(I_{\mathrm{NaP}}\right.$; riluzole, $\left.10 \mu \mathrm{M}\right)$, or $\mathrm{Ca}_{\mathrm{V}}$ channels $\left(\mathrm{CdCl}_{2}, 100 \mu \mathrm{M}\right)$. Presynaptic calyx recordings revealed that 3,5DHPG shifted the activation of $I_{\mathrm{NaP}}$ to more hyperpolarized voltages and increased $I_{\mathrm{NaP}}$ at resting membrane potential. Our data indicate that mGluR I enhances spontaneous glutamate release via regulation of $I_{\mathrm{NaP}}$ and subsequent $\mathrm{Ca}^{2+}$-dependent processes under resting condition.

Key words: auditory; EPSC; mGluR; MNTB; spontaneous glutamate release; voltage-gated sodium channel

Significance Statement

For brain cells to communicate with each other, neurons release chemical messengers, termed neurotransmitters, in response to action potential invasion (evoked release). Neurons also release neurotransmitters spontaneously. Recent work has revealed different release machineries underlying these two release modes, and their different roles in synaptic development and plasticity. Our recent work discovered differential neuromodulation of these two release modes, but the mechanisms are not well understood. The present study showed that activation of group I metabotropic glutamate receptors enhanced spontaneous glutamate release in an auditory brainstem nucleus, while suppressing evoked release. The modulation is dependent on a persistent $\mathrm{Na}^{+}$current and involves subsequent $\mathrm{Ca}^{2+}$ signaling, providing insight into the mechanisms underlying the different release modes in auditory processing.

Received Nov. 21, 2019; revised Aug. 4, 2020; accepted Aug. 7, 2020.

Author contributions: K.P. and Y.L. designed research; K.P., X.W., Y.W., D.L., H.H., and Y.L. performed

research; K.P., X.W., Y.W., D.L., H.H., and Y.L. analyzed data; K.P. and Y.L. wrote the paper.

The authors declare no competing financial interests.

This work was supported by National Institute on Deafness and Other Communication Disorders Grant R01-

DC-016054 (Y.L.), R01-DC-13074 (Y.W.), and R01-DC-016324 (H.H.).

Correspondence should be addressed to Yong Lu at ylu@neomed.edu.

https://doi.org/10.1523/JNEUROSCI.2771-19.2020

Copyright $\odot 2020$ the authors

\section{Introduction}

Spontaneous neurotransmitter release occurs in the absence of presynaptic action potentials (APs; Fatt and Katz, 1950). The traditional views assumed that spontaneous neurotransmitter release shares the same pool of synaptic vesicles with evoked neurotransmitter release and serves no physiological functions. Recent works challenge these views and support the alternative notions that the vesicle pool responsible for spontaneous release may be different from the pool for evoked release and that spontaneous synaptic events play physiological roles in neural signaling that lead to synaptic maturation and homeostasis (for review, 
see Kavalali, 2015). Differential modulation of these two distinct transmitter release modes supports these new concepts, but the underlying mechanisms are not well understood.

The medial nucleus of the trapezoid body (MNTB) is a critical nucleus in the auditory brainstem circuits involved in sound localization (for review, see Grothe et al., 2010). MNTB neurons are excited by well timed and strong glutamatergic inputs from bushy cells in the contralateral anteroventral cochlear nucleus (AVCN) via the giant calyx of Held synapse, ensuring high-speed signal transmission and precise temporal coding of acoustic stimuli for computation of sound localization (for review, see Joris and Trussell, 2018). MNTB neurons also receive strong inhibitory inputs primarily from the ventral nucleus of the trapezoid body (Albrecht et al., 2014), the synaptic strength of which is comparable to the powerful glutamatergic input at the equivalent absolute driving force (Awatramani et al., 2004). We previously showed that group I mGluRs (mGluR I) exert neurotransmitterspecific and release mode-specific modulation of synaptic inhibition in MNTB. Activation of mGluR I increases the frequency and amplitude of glycinergic but not GABAergic spontaneous IPSCs (sIPSCs) and suppresses the GABAergic but not glycinergic evoked IPSCs (Curry et al., 2018). While activation of mGluR I inhibits the evoked glutamatergic transmission via retrograde endocannabinoid signaling in MNTB (Kushmerick et al., 2004), it remains unknown whether and how the spontaneous glutamate release is modulated by mGluR I. Most neurons, potentially including those in MNTB (Awatramani et al., 2004; Albrecht et al., 2014), receive equalizing excitatory and inhibit inputs (Wehr and Zador, 2003; Xue et al., 2014; for review, see Froemke, 2015). Because the balance of excitation and inhibition is a critical feature of sound localizing circuits, as shown in the lateral superior olive (LSO; Magnusson et al., 2008), we hypothesized that spontaneous excitatory transmission in MNTB was enhanced by mGluR I, mirroring the differential modulation of mGluR I on the inhibitory inputs to MNTB (Curry et al., 2018).

If so, what could be the underlying mechanisms? mGluR I enhancement of spontaneous glycine release is dependent on voltage-gated sodium $\left(\mathrm{Na}_{\mathrm{V}}\right.$ ) channels (Curry et al., 2018). In addition to the transient $\mathrm{Na}^{+}$current underlying spike generation, a noninactivating persistent sodium current $\left(I_{\mathrm{NaP}}\right)$ activated at subthreshold voltages impacts the steady state, subthreshold neuronal excitability (for review, see Crill, 1996). Indeed, activation of $I_{\mathrm{NaP}}$ and interaction between $I_{\mathrm{NaP}}$ and a depolarizing glycinergic input increases spontaneous glutamate release in MNTB (Turecek and Trussell, 2001; Huang and Trussell, 2008). Additionally, exaggerated mGluR5 (one of the two members of mGluR I) activity in a fragile X syndrome mouse model enhances $I_{\mathrm{NaP}}$ in entorhinal cortical cells (Deng and Klyachko, 2016). These studies strongly suggest a critical interaction between mGluR I and $I_{\mathrm{NaP}}$ in the regulation of spontaneous neurotransmitter release, leading to our hypothesis that mGluR I enhances spontaneous glutamate release at MNTB via regulation of presynaptic $I_{\mathrm{NaP}}$ in the calyx. Using presynaptic and postsynaptic recordings and immunochemistry, we investigated how mGluR I and $I_{\mathrm{NaP}}$ interact to modulate the spontaneous excitatory transmission in MNTB.

\section{Materials and Methods}

Animals. All animal procedures were approved by the Institutional Animal Care and Use Committees at the Northeast Ohio Medical University (NEOMED), Florida State University, and Tulane University, and were performed in accordance with the National Institutes of Health policies on animal use. C57BL/6J mice were originally purchased from
The Jackson Laboratory and were bred at the universities cited above. Mice were housed in a vivarium with a normal $12 \mathrm{~h}$ light/dark cycle.

Postsynaptic in vitro whole-cell recordings. Coronal brainstem slices ( $\sim 250 \mu \mathrm{m}$ in thickness) were prepared from 2- to 3-week-old mice of both sexes, as previously described (Lu et al., 2007; Curry et al., 2018). Mice were deeply anesthetized with isoflurane and rapidly decapitated. The brainstem was removed and sliced in ice-cold low- $\mathrm{Na}^{+}$artificial CSF (ASCF) containing the following (in $\mathrm{mm}$ ): 250 glycerol, $3 \mathrm{KCl}, 1.2$ $\mathrm{KH}_{2} \mathrm{PO}_{4}, 20 \mathrm{NaHCO}_{3}, 3 \mathrm{HEPES}, 1.2 \mathrm{CaCl}_{2}, 5 \mathrm{MgCl}_{2}$, and 10 glucose, $\mathrm{pH} 7.4$ (when gassed with $95 \% \mathrm{O}_{2}$ and $5 \% \mathrm{CO}_{2}$ ). Slices were incubated in an interface chamber at $34-36^{\circ} \mathrm{C}$ for $\sim 1 \mathrm{~h}$ in normal ACSF containing the following (in $\mathrm{mm}$ ): $130 \mathrm{NaCl}, 20 \mathrm{NaHCO}_{3}, 3 \mathrm{KCl}, 2.4 \mathrm{CaCl}_{2}, 1.3$ $\mathrm{MgSO}_{4}, 1.2 \mathrm{KH}_{2} \mathrm{PO}_{4}$, and 10 glucose, $\mathrm{pH}$ 7.4. For recording, slices were transferred to a $0.5 \mathrm{ml}$ chamber mounted on a Zeiss Axioskop 2 FS Plus Microscope with a $40 \times$ or $63 \times$ water-immersion objective and infrared differential interference contrast optics. The chamber was continuously superfused with ACSF ( $2-5 \mathrm{ml} / \mathrm{min})$ by gravity.

Patch pipettes were drawn on a PP-830 Microelectrode Puller (Narishige) to a 1-2 $\mu \mathrm{m}$ tip diameter using borosilicate glass micropipettes (inner diameter, $0.84 \mathrm{~mm}$; outer diameter, $1.5 \mathrm{~mm}$; World Precision Instruments). The electrodes had resistances between 3 and 6 $\mathrm{M} \Omega$ when filled with internal solution. For current clamp, the internal solution contained the following (in $\mathrm{mm}$ ): $130 \mathrm{~K}$-gluconate, $4.5 \mathrm{MgCl}_{2}$, 4.4 Tris-phosphocreatine, 9 HEPES, 5 EGTA, $4 \mathrm{Na}$-ATP, and $0.48 \mathrm{Na}$ GTP, with pH 7.3, adjusted with $\mathrm{KOH}$, and osmolarity of $\sim 290 \mathrm{mOsm} /$ L. For voltage clamp, $5 \mathrm{~mm}$ QX-314 was added to the internal solution to block $\mathrm{Na}_{\mathrm{V}}$ channels. The liquid junction potential was $10 \mathrm{mV}$, and data were corrected accordingly. Voltage-clamp and current-clamp experiments were performed with AxoPatch 200B and AxoClamp 2B amplifiers (Molecular Devices), respectively. Recordings were performed under near physiological temperatures $\left(34-36^{\circ} \mathrm{C}\right)$ and were obtained at a holding potential of $-60 \mathrm{mV}$ for voltage clamp and at the resting membrane potential (RMP) for current-clamp experiments. Data were lowpass filtered at 5 or $3 \mathrm{kHz}$ and digitized with a Data Acquisition Interface ITC-18 (InstruTech) at $50 \mathrm{kHz}$. Recording protocols were written and run using the acquisition and analysis software AxoGraph X (AxoGraph Scientific).

In all recordings, EPSCs were isolated pharmacologically with $\mathrm{GABA}_{\mathrm{A}}$ receptor antagonist gabazine $(10 \mu \mathrm{M}$; SR95531) and glycine receptor antagonist strychnine ( $1 \mu \mathrm{M}$; Stry). All chemicals were purchased from Sigma-Aldrich except for gabazine, riluzole, and (RS)-3,5-dihydroxyphenylglycine (3,5-DHPG), which were obtained from Tocris Bioscience. 3,5-DHPG was prepared in ACSF at a working concentration of $200 \mu \mathrm{M}$, which is at least threefold higher than its $\mathrm{EC}_{50}$ value (0.7-60 $\mu \mathrm{M}$ depending on animal tissues; for review, see Cartmell and Schoepp, 2000). This was expected to achieve a saturating concentration and thus full activation of group I mGluRs in our experiments.

To record evoked EPSCs (eEPSCs), extracellular stimulation was performed using concentric bipolar electrodes with a tip core diameter of $127 \mu \mathrm{m}$ (World Precision Instruments). The stimulating electrode was placed using an NMN-25 Micromanipulator (Narishige) and was positioned at the ventral brainstem midline to activate the excitatory afferent fibers (Kushmerick et al., 2004). All-or-none eEPSCs were recorded. The stimulus intensity at which maximal response was elicited was chosen to perform experiments with a single-pulse paradigm at a frequency of $0.1 \mathrm{~Hz}$. Group I mGluR agonist 3,5-DHPG $(200 \mu \mathrm{M})$ was bath applied for 2-5 min to one cell per slice. Puff application of 3,5-DHPG $(200 \mu \mathrm{M}$, prepared in ACSF) was done with a glass pipette electrode $(2-4 \mu \mathrm{m}$ tip diameter), the tip of which was placed at a distance of $50-100 \mu \mathrm{m}$ from the recorded cell using an NMN-25 Micromanipulator (Narishige). The shank of the puff electrode was connected to a Picospritzer (General Valve) for pressure ejection (at $\sim 68.9 \mathrm{kPa}$; i.e., $10 \mathrm{psi}$ ) of the ACSF containing 3,5-DHPG. Other pharmacological agents were also bath applied. Typically, responses were averaged from a minimum of six eEPSC traces per drug condition for further data analyses.

Spontaneous EPSCs (sEPSCs) are defined as recorded events that occur in the absence of external (electrical) stimulation, and therefore consist of both miniature EPSCs (mEPSCs), which are AP-independent events because of univesicular release (UVR), and additional sEPSC 
events that may be AP- or depolarization-dependent events including primarily both UVR and possibly multivesicular release (MVR; for review, see Rudolph et al., 2015; for possible MVR at MNTB, see Taschenberger et al., 2002; see Discussion below). mEPSCs were recorded in the presence of tetrodotoxin (TTX; $1 \mu \mathrm{M}$ ), a blocker for $\mathrm{Na}_{\mathrm{V}}$ channels. In a subset of experiments, the following additional antagonists were bath applied in the presence of 3,5-DHPG: mGluR1a antagonist (LY367385, $50 \mu \mathrm{M}$ ), mGluR5 antagonist (MPEP, $10 \mu \mathrm{M})$, voltage-gated $\mathrm{Ca}^{2+}$ channels blocker $\left(\mathrm{CdCl}_{2}, 100 \mu \mathrm{M}\right)$, and $I_{\mathrm{NaP}}$ blocker (riluzole, $10 \mu \mathrm{M}$ ).

Presynaptic (calyx of Held) in vitro whole-cell recordings. The giant glutamatergic terminal calyx of Held renders direct recordings of presynaptic terminals possible (Forsythe, 1994; Borst et al., 1995), including direct recording of presynaptic $I_{\mathrm{NaP}}$ (Huang and Trussell, 2008). Brainstem slices containing the MNTB were prepared from P8-P10 and P14-18 mice of either sex as previously described (Zhang and Huang, 2017). Briefly, mouse brainstems were dissected and $210-\mu \mathrm{m}$-thick sections were sliced using a vibratome (VT1200S, Leica) in ice-cold, low$\mathrm{Ca}^{2+}$, low- $\mathrm{Na}^{+}$saline, which contained the following (in $\mathrm{mM}$ ): $230 \mathrm{su}-$ crose, 10 glucose, $2.5 \mathrm{KCl}, 3 \mathrm{MgCl}_{2}, 0.1 \mathrm{CaCl}_{2}, 1.25 \mathrm{NaH}_{2} \mathrm{PO}_{4}, 25$ $\mathrm{NaHCO}_{3}, 0.4$ ascorbic acid, 3 myo-inositol, and $2 \mathrm{Na}$-pyruvate, bubbled with $95 \% \mathrm{O}_{2}$ and $5 \% \mathrm{CO}_{2}$. Slices were immediately incubated at $32^{\circ} \mathrm{C}$ for 20-40 min and subsequently stored at room temperature in normal ACSF containing the following (in $\mathrm{mm}$ ): $125 \mathrm{NaCl}, 10$ glucose, $2.5 \mathrm{KCl}$, $1.8 \mathrm{MgCl}_{2}, 1.2 \mathrm{CaCl}_{2}, 1.25 \mathrm{NaH}_{2} \mathrm{PO}_{4}, 25 \mathrm{NaHCO}_{3}, 0.4$ ascorbic acid, 3 myo-inositol, and 2 Na-pyruvate, $\mathrm{pH} 7.4$ (when bubbled with $95 \% \mathrm{O}_{2}$ and $5 \% \mathrm{CO}_{2}$ ).

Slices were transferred to a recording chamber and were continually perfused with ACSF (2-3 ml/min) warmed to $\sim 32^{\circ} \mathrm{C}$ (P8-P10 mice) and $34-36^{\circ} \mathrm{C}$ (P14-P18 mice) by an in-line heater (Warner Instruments). Neurons were visualized using an Olympus BX51 microscope with a $60 \times$ water-immersion objective and custom infrared Dodt gradient contrast optics. Whole-cell patch-clamp recordings were performed with a Multiclamp 700B amplifier (Molecular Devices). Pipettes pulled from thick-walled borosilicate glass capillaries (World Precision Instruments) had open tip resistances of 3-5 M $\Omega$ for the presynaptic recording. Series resistance $\left(R_{s} ; 6-25 M \Omega\right)$ was compensated by up to $70 \%$ (bandwidth, $3 \mathrm{kHz}$ ). The $\mathrm{R}_{\mathrm{s}}$ was of a large variation, perhaps because of intrinsic properties of the presynaptic terminals and likely associated with technically challenging presynaptic recordings. However, the $R_{s}$ values in this study are not different from those obtained from the same type of preparations in previous reports (Huang and Trussell, 2008, 2011). Signals were filtered at $10 \mathrm{kHz}$ and sampled at $20 \mathrm{kHz}$.

For presynaptic voltage-clamp experiments, pipettes contained the following (in mM): 120 Cs-methanesulfonate, $10 \mathrm{CsCl}, 10$ TEA-Cl, 1 $\mathrm{MgCl}_{2}, 10$ HEPES, 5 EGTA, 0.4 Tris-GTP, $3 \mathrm{Mg}$-ATP, and $5 \mathrm{Na}_{2}$-phosphocreatine, $292 \mathrm{mOsm} / \mathrm{L}$, and $\mathrm{pH} 7.3$ with $\mathrm{CsOH}$. To isolate presynaptic $\mathrm{Na}^{+}$currents in response to voltage steps or ramps, TEA-Cl $(10 \mathrm{mM})$, and 4-AP (2 mM) and $\mathrm{CdCl}_{2}(200 \mu \mathrm{M})$ were added to ACSF, substituting for $\mathrm{NaCl}$ with equal osmolarity. Liquid junction potential was measured $(-10 \mathrm{mV})$ and reported voltages were appropriately adjusted. Drugs were applied by bath perfusion. 3,5-DHPG and TTX were stored as aqueous stock solutions at $-20^{\circ} \mathrm{C}$.

Immunocytochemistry and confocal microscopy imaging. P14 mice $(n=5)$ were anesthetized with a mixture of ketamine and xylazine, and were transcardially perfused with $0.9 \%$ saline followed by $4 \%$ paraformaldehyde in phosphate buffer (PB). Brains were removed from the skull, postfixed overnight in the same fixative and then transferred to $30 \%$ sucrose in PB until they sank.

Brains were sectioned in the coronal plane at $30 \mu \mathrm{m}$ on a freezing sliding microtome. Each section was collected in $0.01 \mathrm{M}$ PBS. Alternate serial sections were immunocytochemically double stained for antimGluR5 (1:1000; rabbit monoclonal, catalog \#ab76316, Abcam; RRID: AB_1523944) or anti-mGluR5 (1:500; rabbit polyclonal, catalog \#ab5675, Millipore; RRID:AB_2295173), with anti- synaptic vesicle glycoprotein 2 (SV2; 1:1000; mouse monoclonal, catalog \#SV2, Developmental Studies Hybridoma Bank; RRID:AB_2315387) antibodies. Briefly, free-floating sections were incubated with primary antibody solutions diluted in PBS with $0.3 \%$ Triton X-100 overnight at $4^{\circ} \mathrm{C}$, followed by Life Technologies
Alexa Fluor secondary antibodies (1:1000 overnight at $4^{\circ} \mathrm{C}$; Thermo Fisher Scientific). Sections were then mounted on gelatin-coated slides and coverslipped with Fluoromount-G mounting medium (Southern Biotech). Images were captured with a Leica SP8 and an Olympus FV1200 confocal microscope. Image brightness, $\gamma$, and contrast adjustments were performed in Adobe Photoshop (Adobe Systems). All adjustments were applied equally to all images of the same set of staining from the same animal.

Experimental design and statistical analyses. sEPSCs were detected by a template using a function for product of exponentials, $f(t)=[1-\exp$ $(-t /$ rise time $)] \times \exp (-t /$ decay tau $)$, where $t$ stands for time and tau for time constant. The values of the parameters for the template are as follows: amplitude of $-30 \mathrm{pA}$, rise time of $0.3 \mathrm{~ms}$, decay tau of $0.5 \mathrm{~ms}$, with a template baseline of $1 \mathrm{~ms}$ and a template length of $3 \mathrm{~ms}$. These parameters were determined based on the averaged trace of visually detected synaptic events. The detection threshold is typically 2.5 -fold the noise $\mathrm{SD}$, which detects most of the events with the least number of false-positive results. The average of detected events for each cell was obtained using AxoGraph to measure the amplitude, $10-90 \%$ rise time, and decay tau. These parameters were typically averaged from $60 \mathrm{~s}$ periods from each condition: control (Ctrl), drug, and wash. For eEPSC experiments, the peak amplitude of each eEPSC was measured after each stimulus. Averages were obtained from the first minute of the control period, the last minute of the group I mGluR agonist application (3,5-DHPG), and the last minute of the wash period, and were normalized for individual experiments by dividing the peak amplitude of individual eEPSCs by the average eEPSC amplitude under the control condition.

Voltage-clamp data obtained from calyx recordings were analyzed using Clampfit (Molecular Devices) and Igor (WaveMetrics). The detection of the activation threshold for $I_{\mathrm{NaP}}$ was determined from $1 \mathrm{kHz}$-filtered ramp data by extrapolating a line fitted between -100 and $-90 \mathrm{mV}$; the point of deviation from this line (typically by several picoamperes to be obvious by eye; see Fig. 6) was considered as the point of detectable activation of $I_{\mathrm{NaP}}$. Boltzmann functions were used to describe $I_{\mathrm{NaP}}$ activation, as follows: $G=G_{\mathrm{MAX}} /\left(1+\exp \left(-\left(V-V_{\text {half }}\right) /\right.\right.$ $k)$ ), where $G$ is conductance in nanosiemens, $G_{\mathrm{MAX}}$ is the maximal conductance, $V$ is the potential in millivolts, $V_{\text {half }}$ is the voltage for half-maximal activation in millivolts, and $k$ is the slope factor in millivolts.

Graphs were made in Igor (WaveMetrics) and GraphPad Prism8 (GraphPad Software). Mean \pm SEM values are reported. The nonparametric Kolmogorov-Smirnov test was used to assess the significance of shifts in cumulative probability distributions of interevent intervals (IEIs) and amplitude of sEPSC. Data were subject to either repeatedmeasures (RM) one-way ANOVA followed by Holm-Sidak or Tukey's multiple-comparisons test if they passed the Kolmogorov-Smirnov normality test, or Friedman test (nonparametric alternative to the one-way ANOVA with repeated measures) followed by Dunn's multiple-comparisons test if they failed the normality test. Kendall's W value was used to measure the effect size of the Friedman test: $W=\chi^{2} / n(k-1)$, where $\chi^{2}$ is the Friedman test statistic value, $n$ is the sample size, and $k$ is the number of measurements per subject. For significant differences observed in RM one-way ANOVA, a Geisser-Greenhouse correction was conducted for individual sample comparisons. A paired $t$ test was also used for experiments as indicated in the Results. Cohen's $d\left(d_{\text {Cohen }}\right)$ was used to measure the effect size of the paired $t$ test: $d_{\text {Cohen }}=\left(\mathrm{M}_{1}-\mathrm{M}_{2}\right) / \mathrm{SD}_{\text {pooled, }}$, where $\mathrm{M}_{1}$ and $\mathrm{M}_{2}$ are the mean of group 1 and group 2, respectively, and $\mathrm{SD}_{\text {pooled }}$ is the pooled SD for the two groups. A $p$ value of $<0.05$ is considered statistically significant. Statistical analyses were performed using GraphPad Prism 8.

\section{Results}

\section{Activation of mGluR I increases frequency and amplitude of} sEPSC

Activation of mGluR I by a selective agonist 3,5-DHPG inhibits the evoked glutamate release in MNTB (Kushmerick et al., 2004). We hypothesized that 3,5-DHPG enhanced spontaneous glutamate release. This is exactly the opposite modulatory 
direction for the same neurotransmitter in the same neuron, so it is necessary to confirm the effect of 3,5-DHPG on the evoked glutamate release under our recording conditions. In the presence of antagonists for $\mathrm{GABA}_{\mathrm{A}}$ receptors (gabazine, $10 \mu \mathrm{M}$ ) and glycine receptors (strychnine, $1 \mu \mathrm{M}$ ), activation of mGluR I with bath application of 3,5-DHPG $(200 \mu \mathrm{M})$ decreased the amplitude of eEPSCs in all five cells tested (Fig. $1 A, B$ ), similar to the previous observations in rats (Kushmerick et al., 2004).

We then examined the effect of mGluR I on sEPSCs. Bath application of 3,5-DHPG $(200 \mu \mathrm{M})$ increased the frequency and amplitude of sEPSCs. The effect usually lasted for minutes after washout of the drug (Fig. 1C), a similar observation as for spontaneous glycine release (Curry et al., 2018). We also observed an inward current induced by 3,5-DHPG, with an average of $31.6 \pm$ $5.9 \mathrm{pA}$ at the holding potential of $-60 \mathrm{mV}$ (Fig. $1 D ; n=15$ ). Under 3,5-DHPG, the distribution of sEPSC IEIs was narrower than the control condition (Fig. 1E), and there was a significant shift of the distribution toward shorter IEIs (Fig. 1F; KolmogorovSmirnov test: $p<0.0001 ; n=15)$, reflecting a substantial increase in sEPSC frequency. Normalized sEPSC frequency was significantly increased by 3,5-DHPG (Fig. 1G; DHPG: $7.90 \pm 2.94$; Wash: $1.31 \pm 0.28$; Friedman test: $\chi^{2}(2)=10.13, p=0.0063$, $\mathrm{W}=0.343$; Dunn's multiple-comparisons test: Ctrl vs DHPG, $p=0.0105$; Ctrl vs Wash, $p>0.9999$; DHPG vs Wash, $p=0.0318$; $n=15)$. Under 3,5-DHPG, the distribution of sEPSC amplitude was broader than the control condition. Not only did the mean sEPSC amplitude increase during 3,5-DHPG application, but large sEPSCs $(>200 \mathrm{pA})$ that did not exist in the recordings under the control conditions were observed in some neurons, suggesting possible MVR (Fig. 1H). 3,5-DHPG caused a shift of the distribution toward larger amplitudes (Fig. 1I; Kolmogorov-Smirnov test: $p<0.0001 ; n=15)$. Normalized data showed that sEPSC amplitude was significantly greater under 3,5-DHPG than control (Fig. 1J; DHPG: $1.45 \pm 0.14$, Wash: $1.03 \pm 0.06$; RM one-way ANOVA: $F_{(1.207,16.89)}=8.421, p=0.0074, \eta^{2}=0.3756$; Holm-Sidak multiple-comparisons test: Ctrl vs DHPG, $p=0.0163$; Ctrl vs Wash, $p=0.6289$; DHPG vs Wash, $p=0.0303 ; n=15)$. At the same time, 3,5-DHPG did not change the rise time or the decay time constant (tau) of sEPSCs (Fig. $1 K$; rise time, Ctrl: $0.20 \pm 0.02 \mathrm{~ms}$; DHPG: $0.22 \pm 0.02 \mathrm{~ms}$; Wash: $0.22 \pm 0.03 \mathrm{~ms}$; Friedman test: $\chi^{2}(2)=$ 3.959, $p=0.1381, \mathrm{~W}=0.131$; Dunn's multiple-comparisons test: Ctrl vs DHPG, $p=0.2485$; Ctrl vs Wash, $p>0.9999$; DHPG vs Wash, $p=0.6037 ; n=15$; Fig. $1 L$; decay tau, Ctrl: $0.66 \pm 0.12 \mathrm{~ms}$; DHPG: $0.71 \pm 0.18 \mathrm{~ms}$; Wash: $0.70 \pm 0.16 \mathrm{~ms}$; Friedman test: $\chi^{2}(2)=1.661, p=0.4358, \mathrm{~W}=0.055$; Dunn's multiple-comparisons test: Ctrl vs DHPG, $p>0.9999$; Ctrl vs Wash, $p>0.9999$; DHPG vs Wash, $p=0.6037 ; n=15)$. Because a relatively large range of animal ages was used for this experiment, we performed an analysis to examine whether there was any age effect. The normalized sEPSC frequency or amplitude in response to 3,5-DHPG was plotted against the age of animals. Linear regression analysis revealed no significant correlations $(R=0.07, p=0.802$ for frequency; $R=0.06, p=0.835$ for amplitude; data not shown). These data support the idea that the evoked glutamatergic transmission in MTNB is inhibited, whereas the spontaneous glutamatergic transmission is facilitated by $3,5-\mathrm{DHPG}$, demonstrating differential modulation of evoked and spontaneous glutamate release in MNTB neurons by activation of mGluR I.

\section{mGluR I located at the excitatory synapse mediate the modulation}

MNTB receives its major excitatory input from contralateral AVCN globular bushy cells. Bath application of 3,5-DHPG (200 $\mu \mathrm{M})$ would activate all mGluR I wherever the receptors are expressed in various nuclei regardless of their locations in the brain slice, including AVCN. There is evidence that activation of mGluR I depolarizes bushy cells in mouse AVCN (Chanda and $\mathrm{Xu}$-Friedman, 2011). The voltage change in the cell body may conduct to terminals and trigger or modulate transmitter release (Alle and Geiger, 2006; Shu et al., 2006). Therefore, to determine whether the modulatory effect of mGluR I is mediated by the excitatory synapse at MNTB, we made local puff application of 3,5-DHPG $(200 \mu \mathrm{M})$ to the recorded MNTB neurons, which elicited the same effects on sEPSCs as bath application (Fig. 2A). An inward current was induced (Fig. $2 B ; 15.6 \pm 2.8$ pA, $n=11$ ). sEPSC frequency and amplitude were significantly increased (Fig. 2C; for normalized frequency, DHPG: $17.38 \pm 9.84$, Wash: $0.99 \pm 0.16$; Friedman test: $\chi^{2}(2)=14.36, p=0.0074, \mathrm{~W}=0.652$; Dunn's multiple-comparisons test: Ctrl vs DHPG, $p=0.0167$; Ctrl vs Wash, $p>0.9999$; DHPG vs Wash, $p=0.0009 ; n=11$; Fig. 2D; for normalized amplitude, DHPG: $2.00 \pm 0.37$, Wash: $1.05 \pm 0.10$; Friedman test: $\chi^{2}(2)=9.60, p=0.0075, \mathrm{~W}=0.436$; Dunn's multiple-comparisons test: Ctrl vs DHPG, $p=0.0315$; Ctrl vs Wash, $p>0.9999$; DHPG vs Wash, $p=0.0315 ; n=11$ ), and no significant changes in sEPSC kinetics were detected (Fig. $2 E, F ; n=11)$.

\section{3,5-DHPG modulation of sEPSC is via both mGluR1 and mGluR5}

Group I mGluRs include two members, mGluR1 and mGluR5. 3,5-DHPG can activate both, and selective agonists for each member are not yet available. To determine activation of which members enhanced sEPSC, we applied mGluR1a antagonist LY367385 $(50 \mu \mathrm{M})$ or mGluR5 antagonist MPEP $(10 \mu \mathrm{M})$ separately for $\sim 5-10 \mathrm{~min}$, during which 3,5-DHPG was applied. Either LY367385 or MPEP eliminated the effects of 3,5-DHPG on sEPSCs (Fig. $3 A-F$ ), with relatively large variations among different cells when MPEP was applied. There were no significant differences in sEPSC frequency and amplitude between control and LY367385 + 3,5-DHPG (Fig. 3B; for normalized frequency, LY367385: $0.94 \pm$ 0.06; LY367385 + DHPG: $0.98 \pm 0.10$; Wash: $1.10 \pm 0.06 ;$ RM one-way ANOVA: $F_{(1.719,10.31)}=1.212, p=$ 0.3290, $\eta^{2}=0.1681$; Holm-Sidak multiple-comparisons test: Ctrl vs LY367385, $p=0.8014$; Ctrl vs LY367365 + DHPG, $p=0.8864$; $n=7$; Fig. $3 C$; for normalized amplitude, LY367385: $1.08 \pm 0.13$; LY367385 \pm DHPG: $1.09 \pm 0.16$; Wash: $0.94 \pm 0.14$; Friedman test: $\chi^{2}(3)=1.435 ; p=0.6974, \mathrm{~W}=0.068$; Dunn's multiple-comparisons test: Ctrl vs LY367385, $p>0.9999$; Ctrl vs LY367385 + DHPG, $p>0.9999 ; n=7)$. Similarly, no significant differences were detected between control and MPEP + 3,5-DHPG (Fig. 3E; for normalized frequency, MPEP: $1.02 \pm 0.10$; MPEP + DHPG: $2.51 \pm 0.63$; Wash: $1.14 \pm 0.18$; Friedman test: $\chi^{2}(3)=8.309$; $p=0.04, \mathrm{~W}=0.197$; Dunn's multiple-comparisons test: Ctrl vs MPEP, $p>0.9999$; Ctrl vs MPEP+DHPG, $p=0.3422 ; n=14$; Fig. $3 F$; for normalized amplitude, MPEP: $0.96 \pm 0.04$; MPEP + DHPG: $1.11 \pm 0.07$; Wash: $0.97 \pm 0.07$; RM one-way ANOVA: $F_{(1.757,22.84)}=1.865, p=0.1808, \eta^{2}=0.1255$; Holm-Sidak multiple-comparisons test: Ctrl vs MPEP, $p=0.7789$; Ctrl vs MPEP+ DHPG, $p=0.4181 ; n=14)$. While the averaged data showed that either LY36735 $(50 \mu \mathrm{M})$ or MPEP $(10 \mu \mathrm{M})$ abolished the modulation, in some individual cells, neither of the antagonists completely blocked the 3,5-DHPG effects. This was especially obvious in a few cells, in which the sEPSC frequency was increased substantially by 3,5-DHPG in the presence of MPEP (Fig. 3E). Therefore, we applied both antagonists for $\sim 5-10 \mathrm{~min}$, during which we applied 3,5-DHPG (200 $\mu \mathrm{M}$; Fig. 3G). Application of 
A

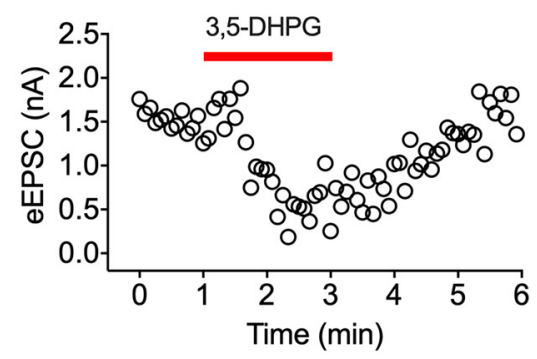

C

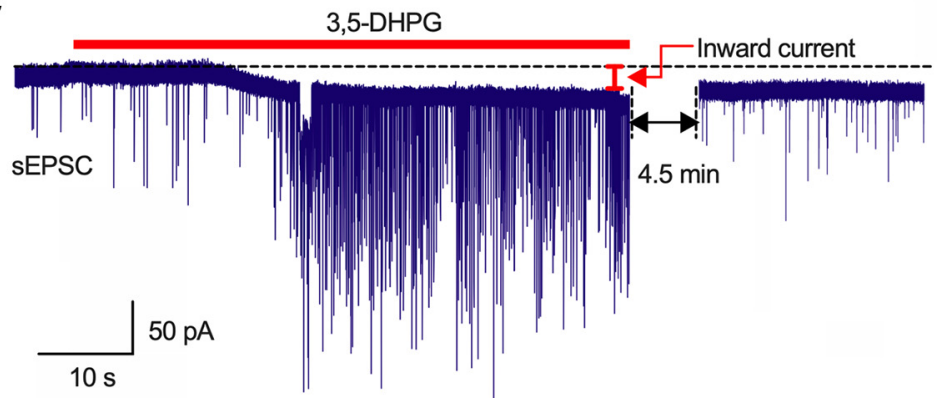

B

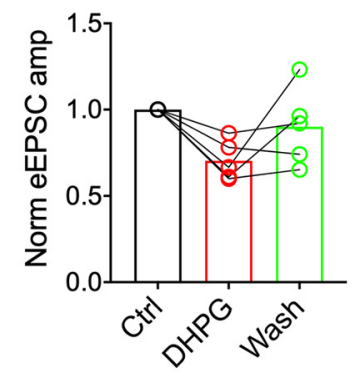

||| || | ||| | ||||||||| |||||| || |||||||||||||||

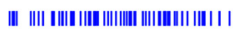
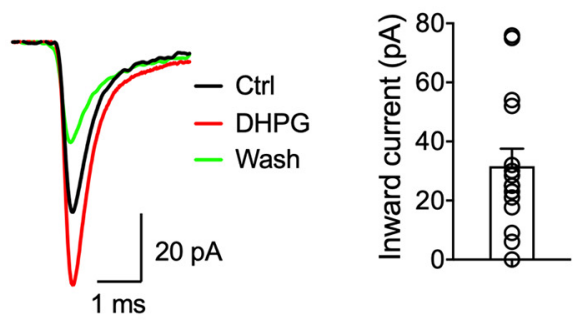

E

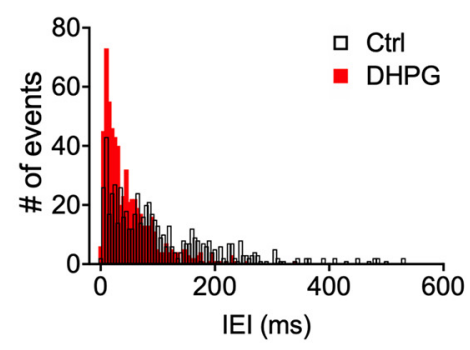

H

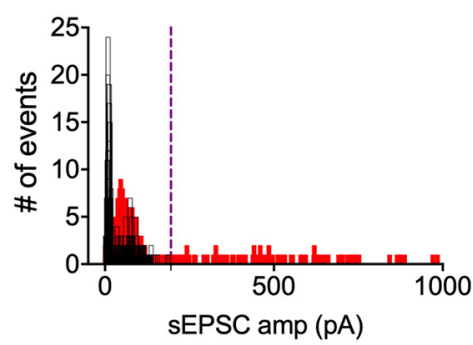

$\mathbf{F}$

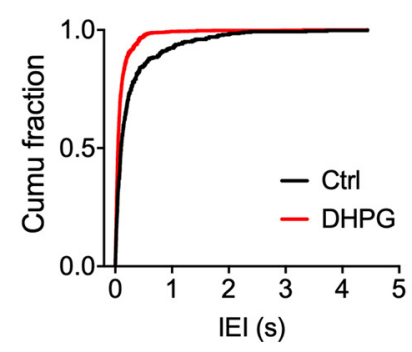

I

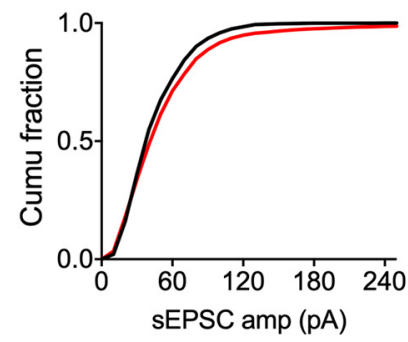

G

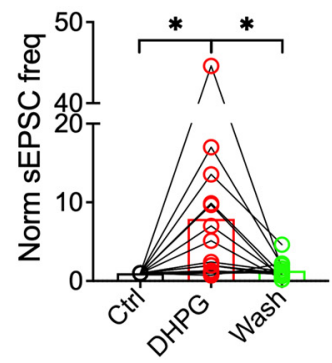

J

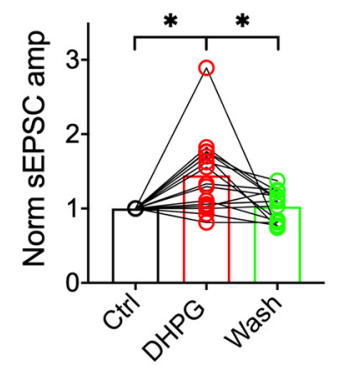

K

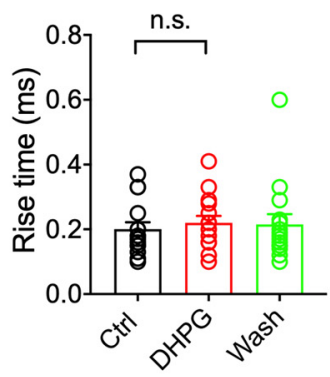

$\mathbf{L}$

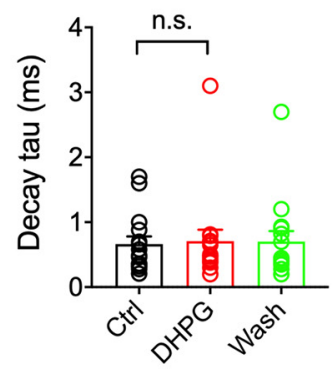

Figure 1. Differential mGluR I modulation of eEPSC and sEPSC. $\boldsymbol{A}, \boldsymbol{B}$, An agonist for mGluR I, 3,5-DHPG (200 $\mu \mathrm{m})$ inhibited eEPSCs in MNTB neurons ( $n=5)$, consistent with published results (Kushmerick et al., 2004). Amp, Amplitude; Norm, normalized. C, Bath application of 3,5-DHPG (200 $\mu \mathrm{m}$ ) produced an inward current and increased sEPSCs in the sample neuron. The instantaneous frequency and amplitude of sEPSC reaches the highest during 3,5-DHPG application. Inset, Averaged sEPSC traces from the three conditions superimposed at a larger time scale. $\mathbf{D}$, Inward current induced by 3,5-DHPG $(n=15)$. $\boldsymbol{E}$, Under 3,5-DHPG (red), the distribution of sEPSC IEls was narrower than the control (black) condition. $\boldsymbol{F}$, Cumulative probability analysis of the IEls $(n=15)$. The leftward shift of the distribution under 3,5-DHPG reflects the increase in frequency compared with control. Kolmogorov-Smirnov analysis, $p<0.0001$. G, 3,5-DHPG significantly increased sEPSC frequency $(n=15)$. Freq, Frequency. $\boldsymbol{H}$, Under 3,5-DHPG, the distribution of sEPSC amplitude of a different sample cell is wider than the control condition, extending well beyond the dashed vertical line that indicates the maximal sEPSC amplitude under the control condition, suggesting possible multivesicular release under 3,5-DHPG. I, Cumulative probability analysis of the amplitude of sEPSCS $(n=15)$. The rightward shift of the distribution under 3,5-DHPG reflects the increase in amplitude compared with control (cutoff, $250 \mathrm{pA})$. KolmogorovSmirnov analysis, $p<0.001$. J, 3,5-DHPG significantly increased the sEPSC amplitude $(n=15)$. $\boldsymbol{K}, L, 3,5$-DHPG did not affect the kinetics of sEPSCS $(n=15)$. In this and subsequent figures, the mean \pm SEM values are shown, with each dot representing the value of one individual cell. ${ }^{*} p<0.05,{ }^{* *} p<0.01$, and ${ }^{* * *} p<0.001$. n.s.: not significant, $p>0.05$. 
A

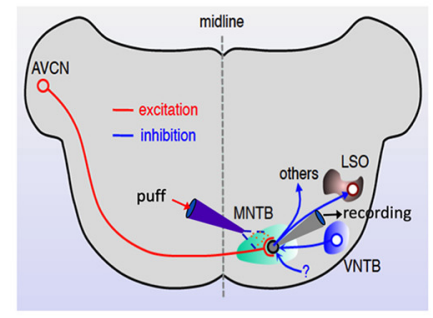

B

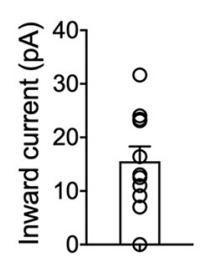

C

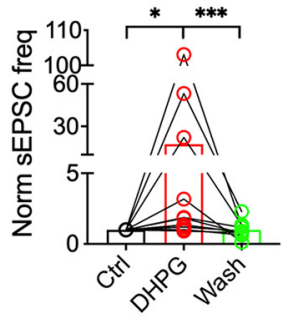

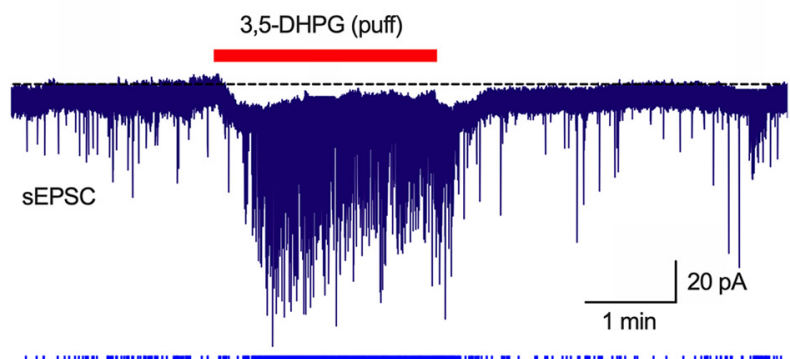

$\mathbf{E}$

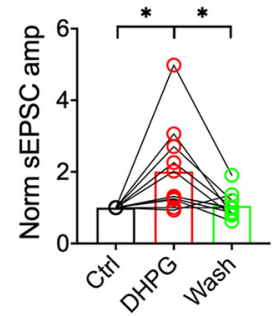

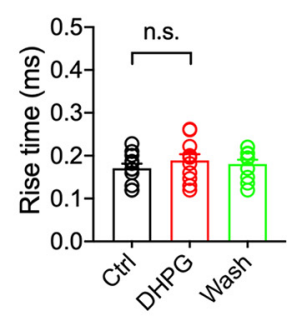

$\mathbf{F}$

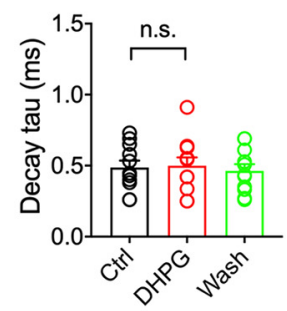

Figure 2. mGluR I located at the excitatory synapse mediates the modulation. $A$, Left, Schematic diagram showing puff application to the recorded MNTB neuron. Right, Puff application of 3,5-DHPG $(200 \mu \mathrm{m})$ produced an inward current and a robust enhancement of sEPSCs in the recorded MNTB neuron. $\boldsymbol{B}$, Inward current induced by puff application of 3,5-DHPG $(n=11)$. $\boldsymbol{C}$, The frequency of sEPSCS was significantly increased by puffed 3,5-DHPG $(n=11)$. D. The amplitude of sEPSCs was also significantly increased $(n=11)$. $\boldsymbol{E}, \boldsymbol{F}$, Puffed 3,5-DHPG did not affect the kinetics of sEPSCS $(n=11)$.

both antagonists completely abolished the 3,5-DHPG effects (Fig. $3 \mathrm{H}$; for normalized frequency, LY367385 + MPEP: $0.72 \pm 0.16$; LY367385 + MPEP + DHPG: $0.69 \pm 0.19$; Wash: 0.72 \pm 0.17; RM one-way ANOVA: $F_{(1.583,6.330)}=2.217, p=0.1873, \eta^{2}=0.3566$; Holm-Sidak multiple-comparisons test: Ctrl vs LY367385+ MPEP, $p=0.6626$; Ctrl vs LY367385 + MPEP + DHPG, $p=$ $0.6626 ; n=5$; Fig. $3 I$; for normalized amplitude, LY367385+ MPEP: $0.87 \pm 0.06$; LY367385 + MPEP + DHPG: $0.82 \pm 0.05$; Wash: $0.86 \pm 0.06 ; \mathrm{RM}$ one-way ANOVA: $F_{(1.428,5.714)}=6.575$; $p=0.0384, \eta^{2}=0.6248$; Holm-Sidak multiple-comparisons test: Ctrl vs LY367385 + MPEP, $p=0.2825$; Ctrl vs LY367385 + MPEP + DHPG, $p=0.1189 ; n=5)$. Based on these pharmacological results, we conclude that the modulation involves both mGluR1 and mGluR5, and a functional cross talk between the two members may exist.

To determine the presynaptic or postsynaptic localization of mGluR I, we examined the distribution pattern of mGluR5 immunoreactivity (for mGluR1, see Discussion) relative to the localization of a presynaptic marker SV2. Using a monoclonal antibody (ab76316), mGluR5 immunoreactivity exhibited a punctate and partially membrane-associated pattern in MNTB (Fig. $4 A, B$ ). First, we identified mGluR5 immunoreactivity in a subset of SV2-labeled presynaptic structures (Fig. 4B1-B3, yellow arrows). Second, mGluR5-immunoreactive puncta were detected within the cell bodies of the principle MNTB neurons, as outlined by SV2 staining. Some puncta were localized immediately adjacent to SV2-labeled presynaptic terminals (Fig. 4B1-B3, white arrows), implicating a postsynaptic localization. Other cell groups of the superior olivary complex, such as the LSO, exhibited a more granular appearance of mGluR5 immunoreactivity without large puncta (Fig. 4C1-C3), indicating that the observed mGluR5 puncta in MNTB are not nonspecific background staining.

mGluR5 localization in SV2-labeled presynaptic terminals was also detected using a polyclonal anti-mGluR5 antibody (ab5675; Fig. 4D1-D3, yellow arrows). The somatic localization of mGluR5 appeared more prominent with this antibody compared with ab76316, while presynaptic localization of mGluR5 was also evident (Fig. 4D3, inset). Together, our results demonstrate that mGluR5 is localized in both presynaptic terminals and the cell bodies of postsynaptic neurons in MNTB at P14.

3,5-DHPG modulation of sEPSCs depends on $\mathrm{Na}_{\mathrm{V}}$ channels, and the signaling pathway involves $\mathrm{Ca}_{\mathrm{V}}$ channels

3,5-DHPG modulation of glycinergic sIPSCs is dependent on $\mathrm{Na}_{V}$ channels (Curry et al., 2018). To determine whether 3,5DHPG modulation of sEPSCs also depends on $\mathrm{Na}_{\mathrm{V}}$ channels, a $\mathrm{Na}_{\mathrm{V}}$ channel blocker, TTX $(1 \mu \mathrm{M})$, was applied before and during 3,5-DHPG application. Without TTX, activation of mGluR I by 3,5-DHPG $(200 \mu \mathrm{M})$ increased sEPSC frequency and amplitude (Fig. 5A). In the same cell, TTX application resulted in the recoding of mEPSCs, and TTX completely eliminated the effect of 3,5DHPG (Fig. 5B). Normalized population data showed that 3,5-DHPG application in the presence of TTX did not cause significant changes in mEPSC frequency or amplitude (Fig. 5C; for normalized frequency, DHPG with TTX: $1.11 \pm 0.29$; Wash: $1.94 \pm$ 0.88; Friedman test: $\chi^{2}(2)=4.80 ; p=0.1242, \mathrm{~W}=0.48$; Dunn's multiple-comparisons test: Ctrl vs DHPG, $p>0.9999 ; n=5$; Fig. $5 D$; for normalized amplitude, DHPG with TTX: $1.01 \pm 0.16$; Wash: $1.02 \pm 0.05 ; \mathrm{RM}$ one-way ANOVA: $F_{(1.155,4.621)}=0.008973, p=$ 0.9491, $\eta^{2}=0.0022$; Holm-Sidak multiple-comparisons test: Ctrl vs DHPG, $p=0.9962 ; n=5)$. These results indicate that the 3,5 DHPG modulation is $\mathrm{Na}_{\mathrm{V}}$ channel dependent.

In calyx of Held, small depolarization induced by glycine enhances presynaptic $\mathrm{Ca}^{2+}$ concentration, leading to increased frequency of mEPSCs (Turecek and Trussell, 2001). To test whether 3,5-DHPG modulation of sEPSCs involves $\mathrm{Ca}^{2+}$ signaling, a nonspecific $\mathrm{Ca}_{\mathrm{V}}$ channel blocker, $\mathrm{CdCl}_{2}$, was applied. Without $\mathrm{CdCl}_{2}$, activation of mGluR I by 3,5-DHPG increased sEPSC frequency and amplitude (Fig. 5E). In the same cell, $\mathrm{CdCl}_{2}(100 \mu \mathrm{M})$ eliminated the effect of 3,5-DHPG (Fig. 5F). 
A

mGluR1a antagonist

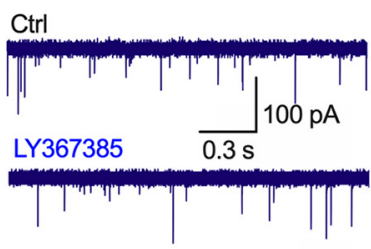

3,5-DHPG + LY367385

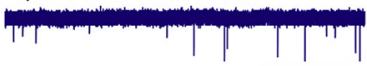

Wash

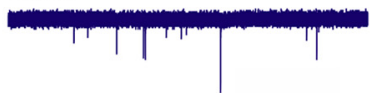

B

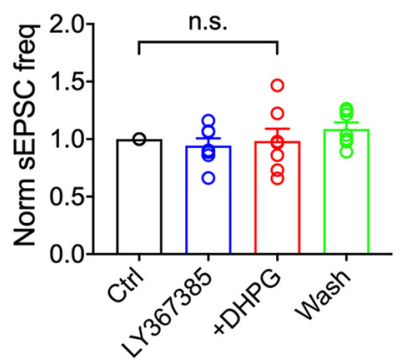

C

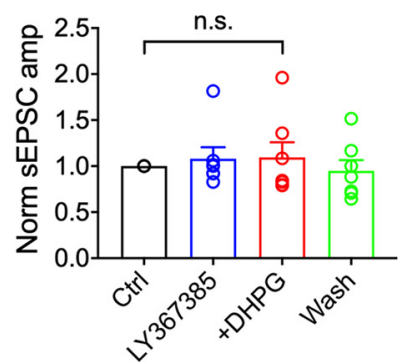

D

mGluR5 antagonist

Ctrl

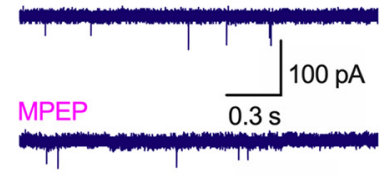

3,5-DHPG + MPEP

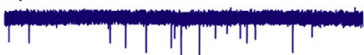

Wash

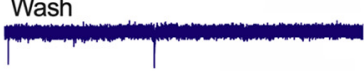

E

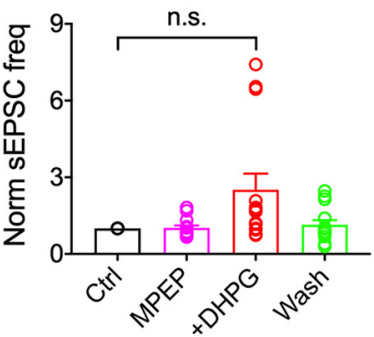

F

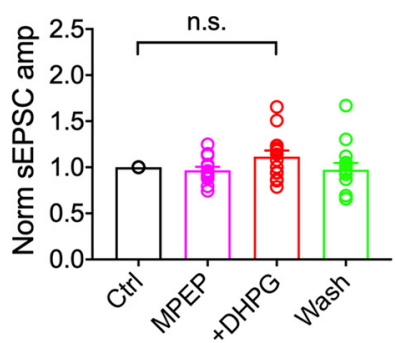

G

mGluR I antagonist

Ctrl

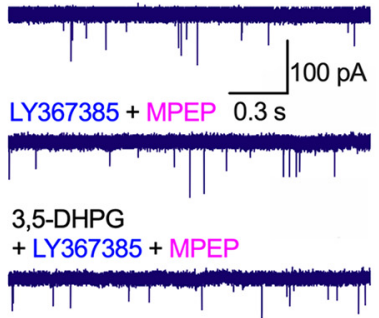

Wash

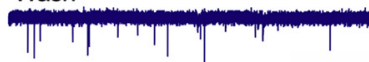

H

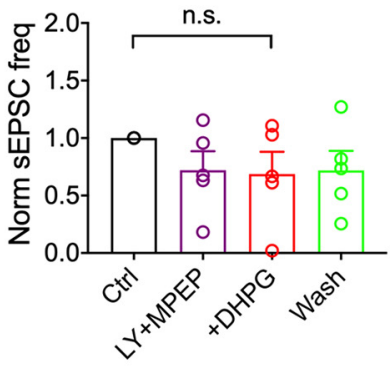

I

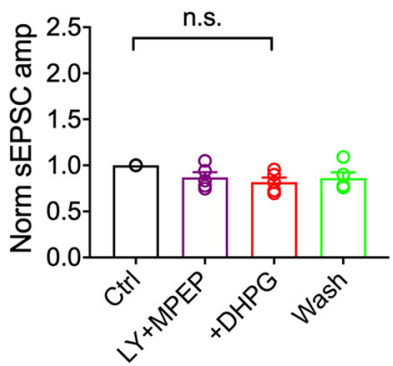

Figure 3. Both mGluR1 and mGluR5 are involved in modulation of sEPSCs, with possible cross talk between the two subtypes. A-C, An antagonist for mGluR1a (LY367385, $50 \mu \mathrm{m}$ ) prevented the effect of 3,5-DHPG on sEPSCS $(n=7)$. D-F, An antagonist for mGluR5 (MPEP, $10 \mu \mathrm{M})$ prevented the effect $(n=14)$, with greater variations. $\mathbf{G}-\boldsymbol{I}$, When combined, the mGluR1a and mGluR5 antagonists completely prevented 3,5-DHPG modulation $(n=5)$.

Normalized population data showed that sEPSC frequency and amplitude were not affected by 3,5-DHPG in the presence of $\mathrm{CdCl}_{2}$ (Fig. $5 \mathrm{G}$; for normalized frequency, $\mathrm{CdCl}_{2}: 0.68 \pm 0.14$; $\mathrm{CdCl}_{2}+$ DHPG: $0.75 \pm 0.21$; RM one-way ANOVA: $F_{(1.059,5.296)}=$ 5.800, $p=0.1880, \eta^{2}=0.5370$; Holm-Sidak multiple-comparisons test: Ctrl vs $\mathrm{CdCl}_{2}, p=0.1352$; $\mathrm{Ctrl}$ vs $\mathrm{CdCl}_{2}+$ DHPG, $p=0.5179$; $n=6$; Fig. $5 \mathrm{H}$; for normalized amplitude, $\mathrm{CdCl}_{2}: 1.15 \pm 0.10 ; \mathrm{CdCl}_{2}$ + DHPG: $1.05 \pm 0.11$; Friedman test: $\chi^{2}(2)=4.333, p=0.11416$, $\mathrm{W}=0.361$; Dunn's multiple-comparisons test: Ctrl vs $\mathrm{CdCl}_{2}$, $p=0.4467 ;$ Ctrl vs $\left.\mathrm{CdCl}_{2}+\mathrm{DHPG}, p>0.9999 ; n=6\right)$. These results support that the signaling pathway underlying the enhancement of sEPSCs by 3,5-DHPG involves $\mathrm{Ca}_{\mathrm{V}}$ channels.

\section{Activation of mGluR I depolarizes membrane and enhances} the $I_{\mathrm{NaP}}$ of calyx of Held

In the calyx of Held, $I_{\mathrm{NaP}}$ amplifies the glycine-induced enhancement of glutamate release (Huang and Trussell, 2008). It is possible that the activation of mGluR I depolarizes the membrane; enhances the $I_{\mathrm{NaP}}$ of calyx of Held, which further depolarizes the membrane; and leads to the enhancement of spontaneous glutamate release. To directly test these ideas, calyx (presynaptic) recordings were performed. The success of such recordings was confirmed by filling the calyx of Held with Alexa Fluor 488 (Fig. $6 A$, inset). Because of the high difficulty level achieving calyx recordings, we first performed the experiments in younger animals (P8-P10) and under lower temperature $\left(32^{\circ} \mathrm{C}\right)$, to achieve sufficient voltage clamp. Under current-clamp configuration, 3,5-DHPG $(200 \mu \mathrm{M})$ depolarized the membrane of calyx of Held (Fig. $6 A$ ) by an average of $3.9 \pm 0.5 \mathrm{mV}$ (Fig. $6 B ; n=7$ ), similar to a previous report in rats (Kushmerick et al., 2004).

$I_{\mathrm{NaP}}$ in the calyx of Held terminal was then studied using voltage-ramp and voltage-step protocols in the presence of $K_{v}$ and $\mathrm{Ca}_{\mathrm{V}}$ channel blockers (see Materials and Methods). In calyxes obtained from $\mathrm{P} 8-\mathrm{P} 10$ mice and recorded at $32^{\circ} \mathrm{C}$, a voltage ramp $(70 \mathrm{mV} / \mathrm{s})$ evoked an inward current, without escaping action current. Bath application of 3,5-DHPG $(200 \mu \mathrm{m})$ shifted the $I_{\mathrm{NaP}}$ activation to more hyperpolarized voltages. The current 

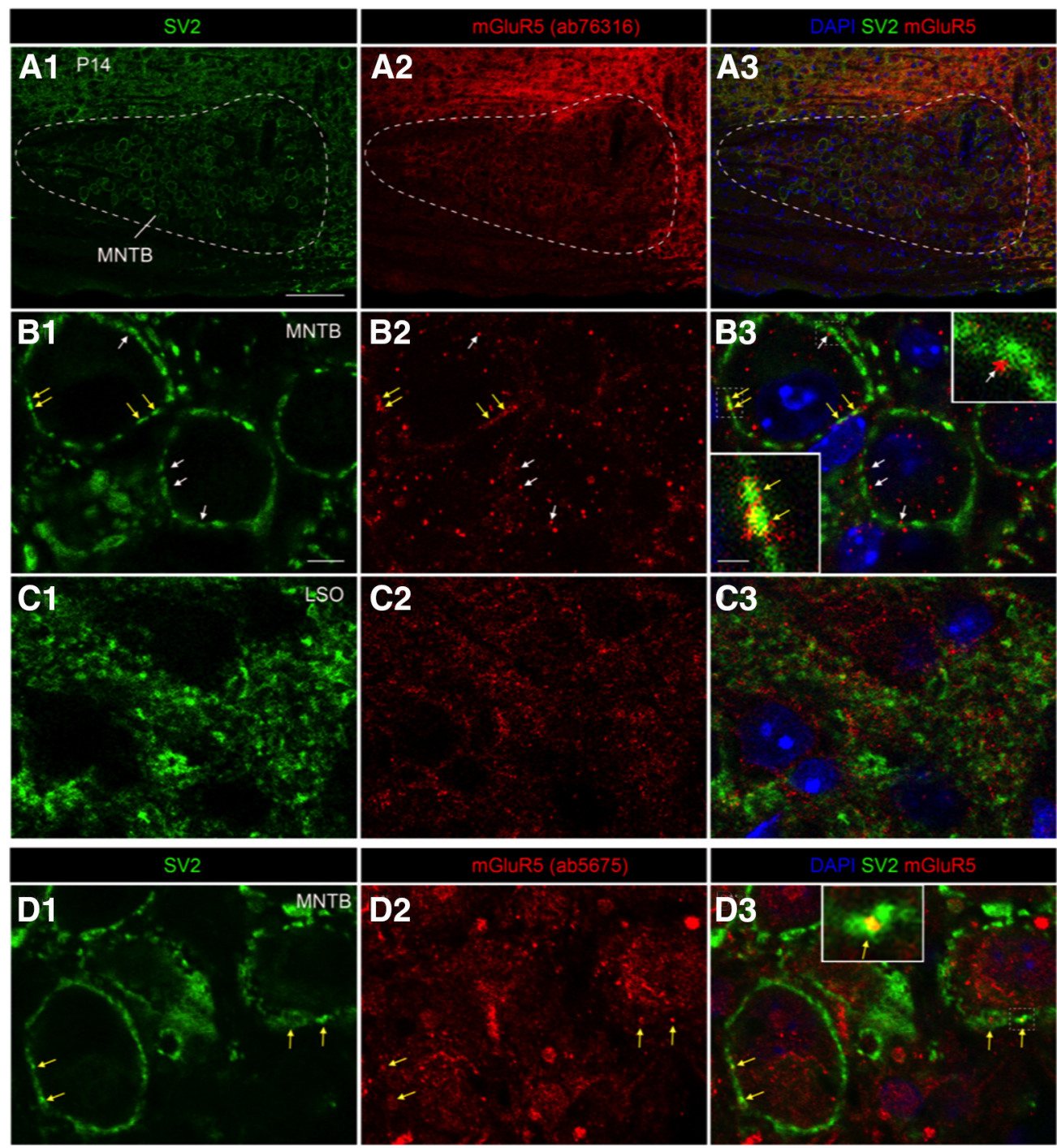

Figure 4. Subcellular localization of mGluR5 in MNTB. Double immunostaining against mGluR5 (red) and presynaptic marker SV2 (green) was performed on P14 transverse brainstem sections containing MNTB. Sections were also counterstained with DAPI (blue). A1-A3, B1-B3 and C1-C3 were taken from sections stained with a monoclonal anti-mGluR5 (ab76316), while D1-D3 was with a polyclonal anti-mGluR5 (ab5675). A1-A3, Low-magnification image of MNTB (outlined by dashed lines). B1-B3, High-magnification images of MNTB. Yellow arrows point to SV2-labeled presynaptic terminals that contain mGluR5 immunoreactivity. White arrows point to examples of mGluR5 puncta that were apposed to the presynaptic structure. Insets are closer views of the boxes in B3. C1-C3, High-magnification images of LSO. Note the lack of large mGluR5 puncta that were observed in MNTB. D1-D3, High-magnification image of ab5675 showing mGluR5 localization in SV2-labeled terminals (yellow arrows) in MNTB. The inset is a closer view of the box in D3, showing colocalization of SV2 and mGluR5. Scale bars: $\boldsymbol{A 1}$ (for $\boldsymbol{A 1 - A 3 )}$, $100 \mu \mathrm{m} ; \boldsymbol{B} 1$ (for $\boldsymbol{B} 1-\boldsymbol{B} 3, \mathbf{C}$-C3, D1-D3), $5 \mu \mathrm{m}$; insets (all insets in $\boldsymbol{B}$ and $\mathbf{D} 3$ ), $1 \mu \mathrm{m}$.

evoked with ramps was fully blocked by TTX (500 nm; Fig. 6C, blue trace), confirming it is a $\mathrm{Na}^{+}$current (Fig. 6C). By subtraction of the $I_{\mathrm{NaP}}$ traces from the trace with TTX (500 nM), the current-voltage relation for $I_{\mathrm{NaP}}$ and the activation threshold were determined (as defined in the Materials and Methods). The enlarged $I_{\mathrm{NaP}}$ traces showed that 3,5-DHPG shifted the activation threshold from $-85.3 \pm 0.8$ to $-88.0 \pm 0.7 \mathrm{mV}$ and largely increased the $I_{\mathrm{NaP}}$ at voltages around RMP (Fig. $6 D$ ), the value of which was reported to be $-75 \mathrm{mV}$ for immature calyces at $32^{\circ} \mathrm{C}$ (Huang and Trussell, 2011, 2014) and at approximately $-74 \mathrm{mV}$ at a more physiological temperature (Sierksma and Borst, 2017). To further explore these activation characteristics, conductance versus voltage plots were constructed using voltage steps. Boltzmann fits revealed that the $V_{\text {half }}$ shifted from $-52.7 \pm 4.1$ to $-56.2 \pm 3.9 \mathrm{mV}$ (Fig. $6 E$; paired $t$ test; $d_{\text {Cohen }}=-0.396, p=0.002$, $n=5)$. At $-75 \mathrm{mV}$, DHPG increased the $I_{\mathrm{NaP}}$ amplitude from $43.7 \pm 15.6$ to $70.6 \pm 21.4 \mathrm{pA}$ (Fig. $6 F$; paired $t$ test: $d_{\text {Cohen }}=0.642$, $p=0.04, n=5)$.
The above voltage-clamp experiments were performed in calyxes obtained from prehearing (P8-P10) mice, and the recordings were done at $32^{\circ} \mathrm{C}$ for practical reasons: relatively higher feasibility in younger animals and sufficient voltage clamp. To be consistent with the conditions for our postsynaptic recordings, we performed the same experiments described above (Fig. 6C-F) in posthearing (P14-P18) mice at more physiological temperatures $\left(34-36^{\circ} \mathrm{C}\right)$. Under these conditions, three of five recorded calyxes generated escaping action currents (data not shown), because of fast activation kinetics of the transient $\mathrm{Na}_{\mathrm{V}}$ currents (Huang and Trussell, 2008; Hu and Bean, 2018). Nonetheless, the effects of 3,5-DHPG on the $I_{\mathrm{NaP}}$ were similar to those observed in prehearing mice (Fig. 6G-J). 3,5-DHPG shifted the activation threshold of $I_{\mathrm{NaP}}$ from $-87.5 \pm 2.6$ to $-90.4 \pm$ $1.7 \mathrm{mV}$ (Fig. $6 \mathrm{G}, H$ ) and shifted the $V_{\text {half }}$ of $I_{\mathrm{NaP}}$ from $-42.6 \pm 3.8$ to $-48.6 \pm 3.3 \mathrm{mV}$ (Fig. $6 I$; paired $t$ test, $d_{\text {Cohen }}=-0.79$, $p=0.005, n=5)$. At $-75 \mathrm{mV}, 3,5-\mathrm{DHPG}$ increased the $I_{\mathrm{NaP}}$ amplitude from $107.6 \pm 69.1$ to $173.1 \pm 70.0 \mathrm{pA}$ (Fig. 6 ; ; paired $t$ 
A

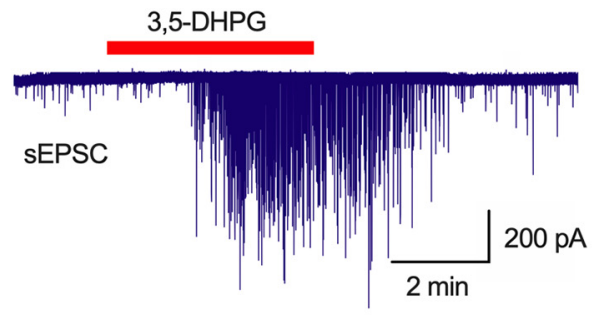

|| | | III ||| || |||| | | || || |||||||| ||| || || ||| | ||

B

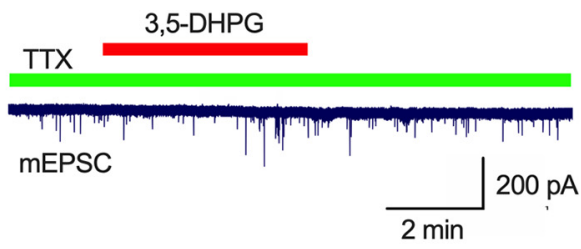

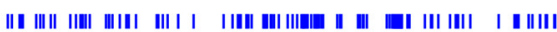

$\mathbf{E}$

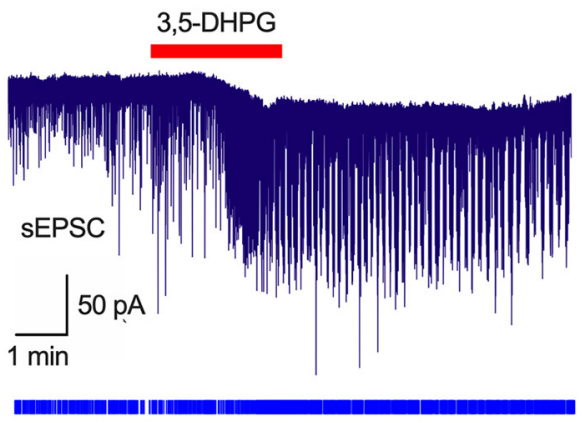

$\mathbf{F}$

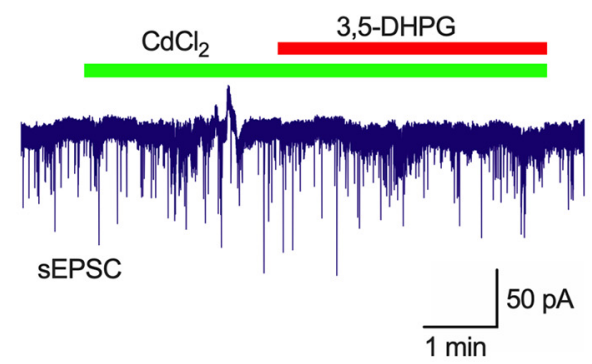

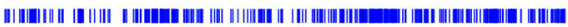

C

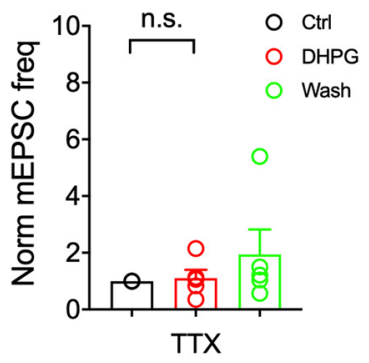

D

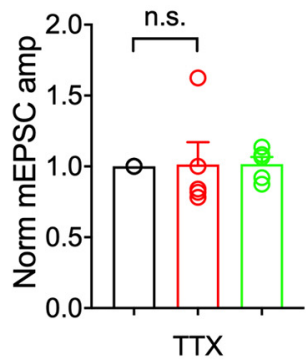

G

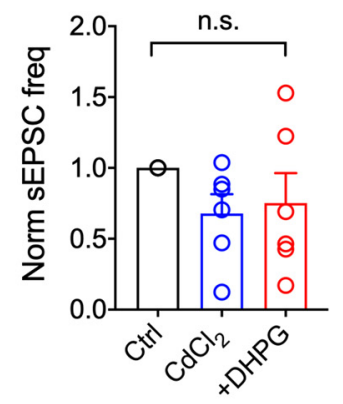

H

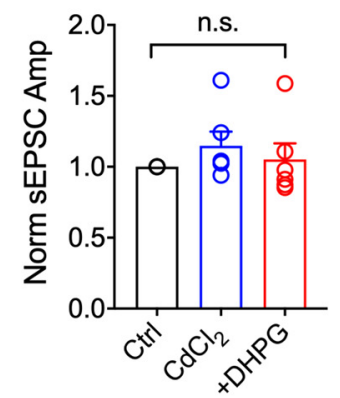

Figure 5. mGluR I modulation of sEPSCs is $\mathrm{Na}_{v}$ channel dependent, and the signaling pathway involves $\mathrm{Ca}_{v}$ channels. $\boldsymbol{A}, \boldsymbol{B}$, Under control conditions, 3,5-DHPG increased the frequency and amplitude of sEPSCs. In the presence of TTX (1 $\mu \mathrm{m}), 3,5-D H P G$ did not affect mEPSCS. $\boldsymbol{C}, \boldsymbol{D}$, Summary of population data with the presence of TTX $(n=5)$. $\boldsymbol{E}$, In another group of MNTB neurons, under control conditions, 3,5-DHPG increased the frequency and amplitude of $s E P S C$. $\boldsymbol{F}$, In the presence of a generic blocker for $\mathrm{Ca}_{\mathrm{v}}$ channels ( $\left.\mathrm{CdCl}_{2}, 100 \mu \mathrm{m}\right), 3,5-\mathrm{DHPG}$ did not affect sEPSCs. G, $\boldsymbol{H}$, Population data for the change in frequency and amplitude of $s E P S C$ in the presence of $\mathrm{CdCl}_{2}(n=6)$.

test, $d_{\text {Cohen }}=0.471, p=0.0417, n=4$; one cell was excluded because the escaping action current prevented measurement of the $I_{\mathrm{NaP}}$ amplitude). These results indicate that mGluR I activation substantially increases the $I_{\mathrm{NaP}}$ in posthearing mice, confirming mGluR modulation of the spontaneous glutamate release in both age groups.

To further support our conclusion, we tested the effect of riluzole, a potent $I_{\mathrm{NaP}}$ inhibitor (Urbani and Belluzzi, 2000), on
sEPSC. Applied at least 5 min before 3,5DHPG application, riluzole $(10 \mu \mathrm{M})$ prevented the effects of 3,5-DHPG on sEPSCs (Fig. 6K). We detected no significant differences in the frequency and amplitude of sEPSCs between control and riluzole + 3,5-DHPG conditions (Fig. $6 L$; for normalized frequency, riluzole: $1.11 \pm$ 0.15; riluzole + DHPG: $1.58 \pm 0.27$; Wash: $1.24 \pm 0.18$; Friedman test: $\chi^{2}(3)=2.356$, $p=0.0519, \mathrm{~W}=0.523$; Holm-Sidak multiple-comparisons test: Ctrl vs riluzole, $p>0.9999$; Ctrl vs riluzole + DHPG, $p>$ 0.9999; $n=15$; Fig. $6 M$; for normalized amplitude, riluzole: $1.05 \pm 0.07$; riluzole + DHPG: $1.14 \pm 0.11$; Wash: $1.05 \pm 0.06$; Friedman test: $\chi^{2}(3)=0.68, p=0.8779$, $\mathrm{W}=0.0151$; Dunn's multiple-comparisons test: Ctrl vs riluzole, $p>0.9999$; Ctrl vs riluzole + DHPG, $p>0.9999 ; n=15)$. These results suggest that mGluR I-mediated enhancement of spontaneous glutamate release occurs via enhancing the presynaptic $I_{\mathrm{NaP}}$.

\section{Enhancement of sEPSCs by mGluR I} does not involve CB1 cannabinoid receptors activated via retrograde signaling

In calyx of Held, activation of postsynaptic mGluR I produces second messengers that diffuse retrogradely into the presynaptic terminal, and it inhibits evoked glutamate release via activation of presynaptic CB1 cannabinoid receptors (CB1Rs; Kushmerick et al., 2004). We designed a set of control experiments to test the involvement of this retrograde signaling pathway in the mGluR I modulation of sEPSCs. First, we tested whether postsynaptic $\mathrm{Ca}^{2+}$ was involved in mGluR I modulation of sEPSCs. The intracellular $\mathrm{Ca}^{2+}$ concentration could be raised because of mGluR I activation through release from internal stores via the phospholipase pathway (for review, see Niswender and Conn, 2010) and was involved in generation of depolarization-induced suppression of excitation (Glitsch et al., 2000). We included a fast $\mathrm{Ca}^{2+}$ chelator (BAPTA, $40 \mathrm{~mm}$ ) in the recording electrodes (the concentration of K-gluconate was reduced accordingly from 130 to $90 \mathrm{~mm}$, to maintain proper osmolarity), and obtained the effects of 3,5DHPG $(200 \mu \mathrm{M})$ on sEPSCs. Kushmerick et al. (2004) showed that including $40 \mathrm{~mm}$ BAPTA in the recording electrodes eliminated the inhibitory effects of 3,5-DHPG on eEPSCs caused by postsynaptic mGluR I activation. In our present study, with $40 \mathrm{~mm}$ BAPTA in the recording electrodes, the modulatory effects of 3,5-DHPG on sEPSCs were still observed (Fig. 7A-C; $n=9$ ), same as those recorded with the regular internal solution (Figs. 1, 2). sEPSC frequency and amplitude were significantly 
A

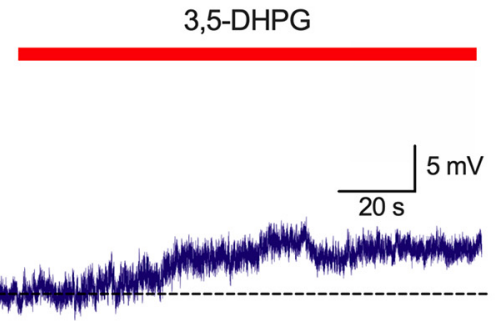

B

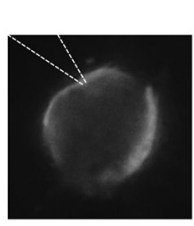

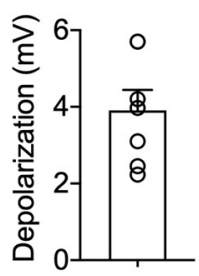

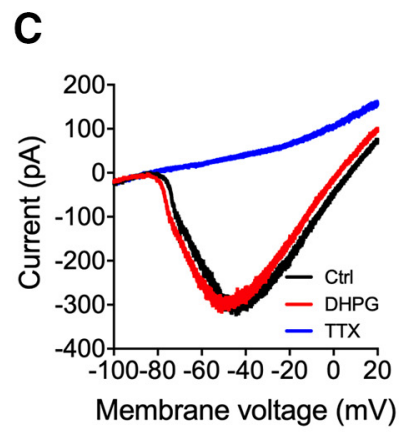

G

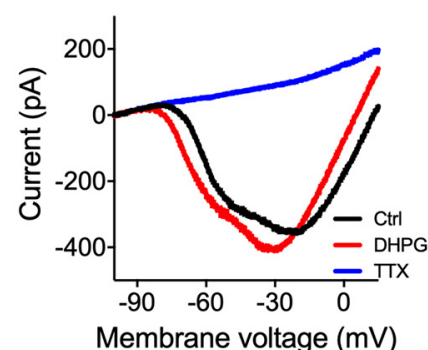

Membrane voltage $(\mathrm{mV})$
D

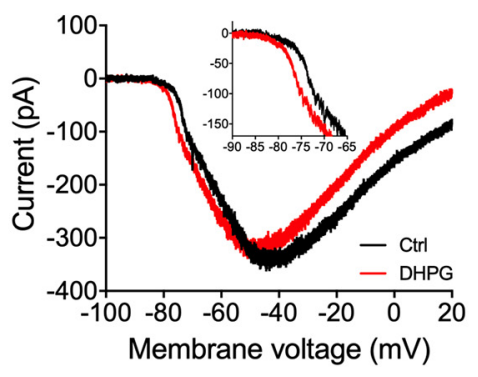

P14-P18; $34-36{ }^{\circ} \mathrm{C}$

H

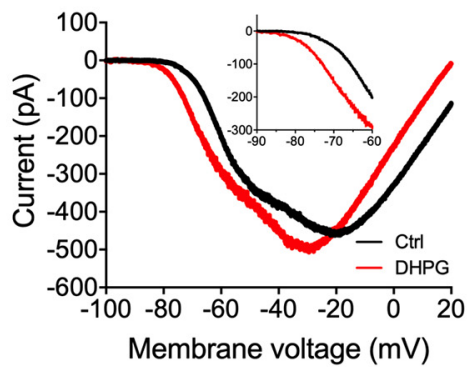

E

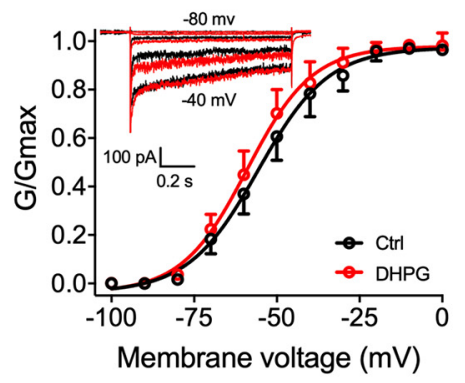

I

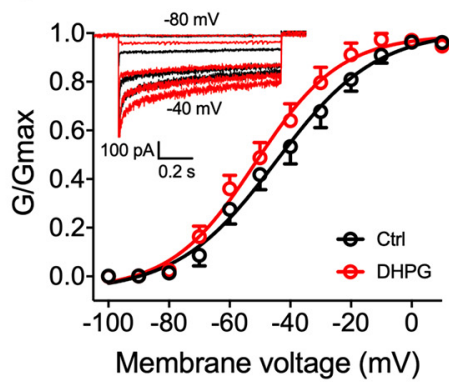

$\mathbf{F}$

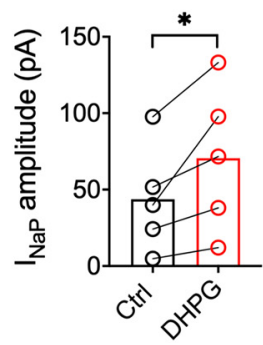

J

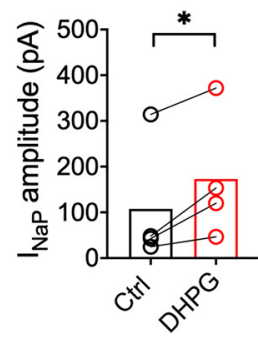

K

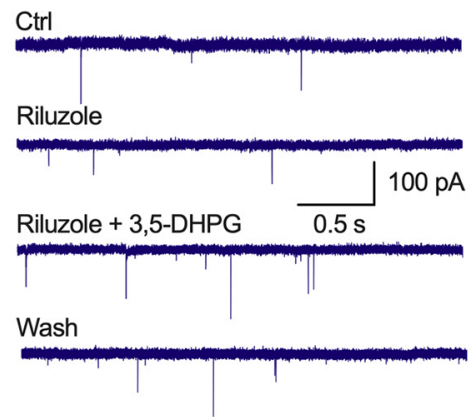

L

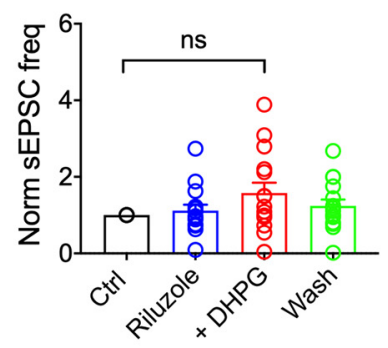

M

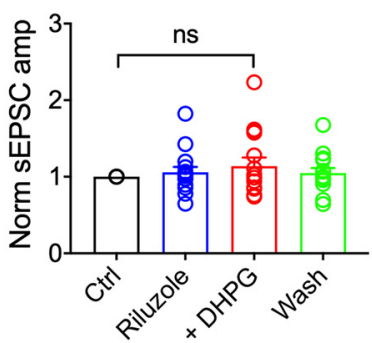

Figure 6. 3,5-DHPG enhances the activation of persistent sodium current $\left(I_{\text {NaP }}\right)$ of calyx of Held, in both prehearing (P8-P10) mice at $32^{\circ} \mathrm{C}$ and posthearing (P14-P18) mice at a more physiological temperature $\left(34-36^{\circ} \mathrm{C}\right)$. A, 3,5-DHPG depolarized the membrane potential of calyx of Held. Inset, Presynaptic recording was confirmed by filling the calyx of Held with Alexa Fluor 488 . $B$, Depolarization of calyx of Held induced by 3,5-DHPG $(n=7)$. C, In prehearing (P8-P10) mice, at $32^{\circ} \mathrm{C}$, a voltage ramp $(70 \mathrm{mV} / \mathrm{s})$ evoked an inward current in a calyx of Held terminal in control (black) and in the presence of 3,5-DHPG (200 $\mu \mathrm{m}$, red). Subsequent addition of TTX $(0.5 \mu \mathrm{m})$ fully blocked the inward current (blue). D, TTX-subtracted traces, with the inset showing the expanded view of activation of the TTX-sensitive current in control (black) and in the presence of 3,5-DHPG (red). $\boldsymbol{E}$, Boltzmann fitting of the conductance voltage curves revealed that 3,5DHPG shifted the $V_{\text {half }}$ to the left toward a more negative voltage. Inset, Representative currents to voltage steps from -80 to $-40 \mathrm{mV}$ (increment of $10 \mathrm{mV}$, duration of $1 \mathrm{~s}$ ). The current amplitude was measured at $750-1000 \mathrm{~ms}$. $\boldsymbol{F}$, At $-75 \mathrm{mV}$, around the resting membrane potential for calyx of Held, bath application of 3,5-DHPG increased the $I_{\text {NaP }}$ amplitude $(n=5)$. G-J, In posthearing (P14-P18) mice, at $34-36^{\circ} \mathrm{C}$, the same experiments and analyses as described above $(\boldsymbol{C} \boldsymbol{F})$ were repeated, and the observations were confirmed $(n=4-5)$. $\boldsymbol{K}-\boldsymbol{M}$, An antagonist for $I_{\text {NaP }}$ (riluzole, $10 \mu \mathrm{m}$ ) largely prevented the effect of 3,5-DHPG on sEPSCS $(n=15)$. 
A

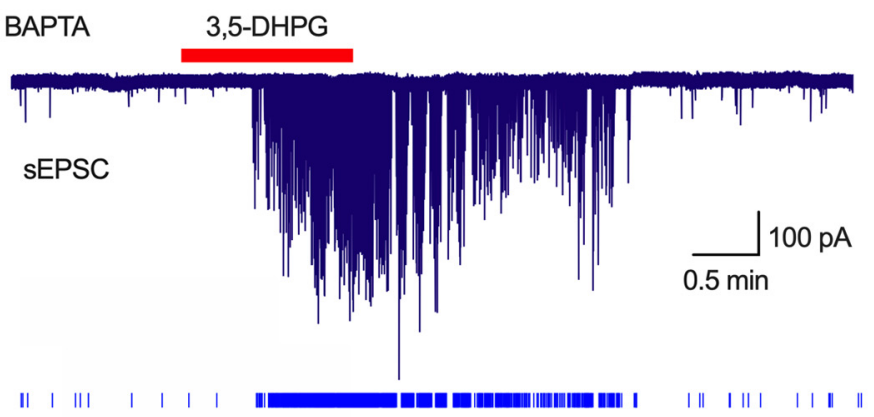

D

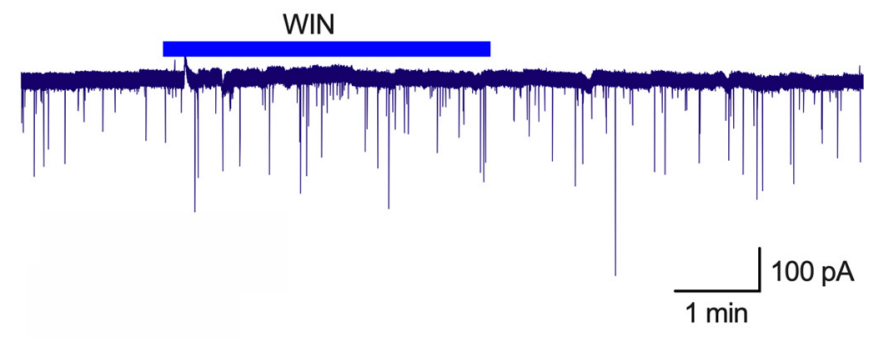

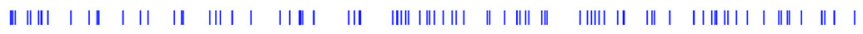

G

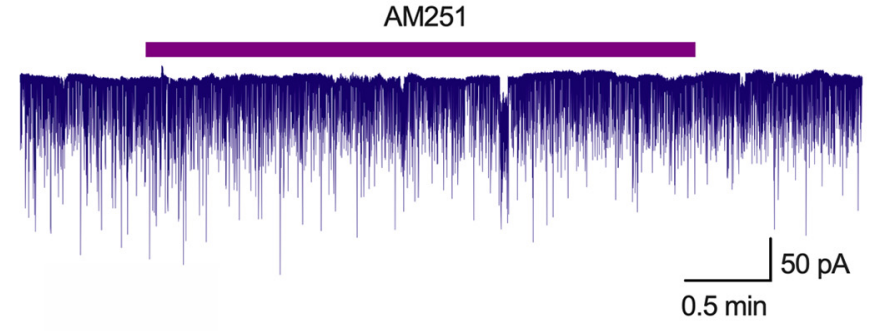

B

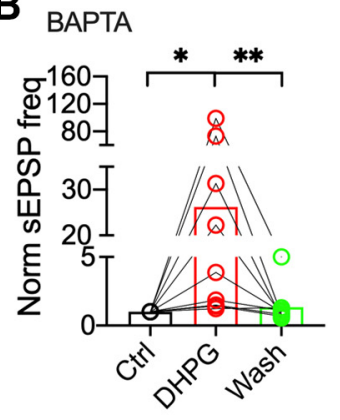

E

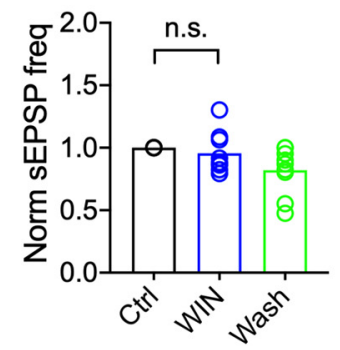

H

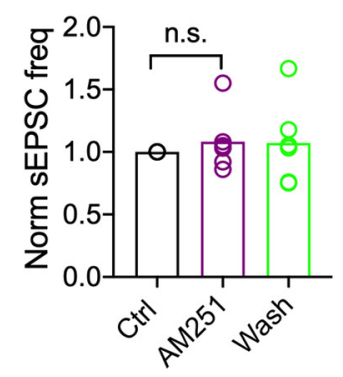

C BAPTA

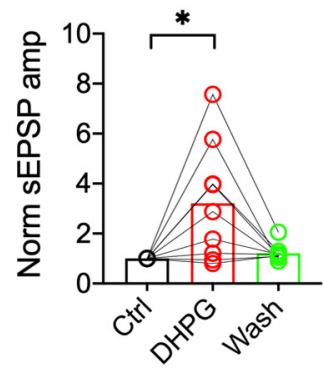

$\mathbf{F}$

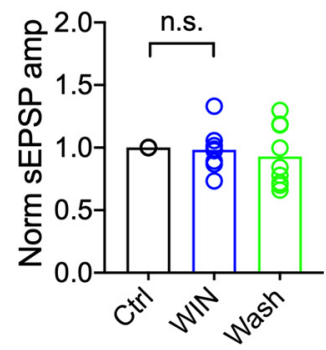

I

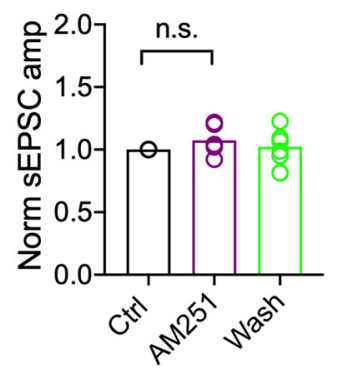

Figure 7. Enhancement of sEPSCs by mGluR I does not involve CB1Rs activated via retrograde signaling. $A-C$, Including a fast $\mathrm{Ca}^{2+}$ chelator, BAPTA (40 mM), in the recording internal solution did not change the effect of 3,5-DHPG $(200 \mu \mathrm{m})$ on sEPSCS $(n=9)$. D-F, CB1R agonist (WIN, $5 \mu \mathrm{m})$ had no effects on sEPSCs $(n=9)$. G-I, CB1R antagonist (AM251, $5 \mu \mathrm{m})$ had no effects on $\mathrm{SEPSCS}(n=6)$.

increased (Fig. 7B; for normalized frequency, DHPG: $26.20 \pm 12.08$; Wash: $1.33 \pm 0.46$; Friedman test: $\chi^{2}(2)=10.89, p=0.0029$; $\mathrm{W}=0.605$; Dunn's multiple-comparisons test: Ctrl vs DHPG, $p=0.0186$; Ctrl vs Wash, $p>0.9999 ;$ DHPG vs Wash, $p=0.0065$; $n=9$; Fig. $7 C$; for normalized amplitude, DHPG: $3.21 \pm 0.78$; Wash: $1.21 \pm 0.11$; Friedman test: $\chi^{2}(2)=6.89, p=0.0307 ; \mathrm{W}=0.382$; Dunn's multiple-comparisons test: Ctrl vs DHPG, $p=0.0286$; Ctrl vs Wash, $p=0.2969$; DHPG vs Wash, $p>0.9999 ; n=9)$. Second, we tested the effects of CB1R agonist (WIN, $5 \mu \mathrm{M}$ ) and found no effects on sEPSCs (Fig. 7D-F; $n=9$ ), indicating that activation of the presynaptic CB1Rs did not affect spontaneous glutamate release. Finally, to exclude the possibility that CB1Rs might be saturated under the rest condition and thus the agonist WIN did not cause further modulation, we tested the effects of CB1R antagonist (AM251, $5 \mu \mathrm{M}$ ). As expected, no significant effects on sEPSCs were detected (Fig. 7G-I;n=6), indicating minimal endogenous activity of CB1Rs in our slice recording conditions. The results of these control experiments further confirmed that presynaptic mGluR I enhanced sEPSCs through signaling pathways inside the presynaptic terminal, without involvement of the CB1Rs that are involved in modulation of eEPSCs and other postsynaptic $\mathrm{Ca}^{2+}$-dependent signaling.
Activation of mGluR I depolarizes membrane potential, increases the frequency and amplitude of spontaneous EPSP, and affects AP generation in MNTB neurons

To investigate the physiological function of the observed modulatory effects of mGluR I activation, current-clamp recordings of MNTB neurons were performed. Consistent with voltage-clamp recordings, puff application of 3,5-DHPG $(200 \mu \mathrm{M})$ depolarized the membrane potential (Fig. $8 A, B ; 4.9 \pm 0.8 \mathrm{mV} ; n=10$ ). Spontaneous EPSP (sEPSP) frequency and amplitude were significantly increased (Fig. 8C; for normalized frequency, DHPG: $5.54 \pm 1.72$; Wash: $1.52 \pm 0.54$; Friedman test: $\chi^{2}(2)=15.44, p<0.0001, \mathrm{~W}=0.772$; Dunn's multiple-comparisons test: Ctrl vs DHPG, $p=0.0016$; Ctrl vs Wash, $p>0.9999$; DHPG vs Wash, $p=0.0036$; $n=10$; Fig. $8 D$; for normalized amplitude, DHPG: $2.29 \pm 0.57$; Wash: $0.98 \pm 0.09$; Friedman test: $\chi^{2}(2)=15.79, p<0.0001, \mathrm{~W}=0.789$; Dunn's multiple-comparisons test: Ctrl vs DHPG, $p=0.0024$; Ctrl vs Wash, $p>0.9999$; DHPG vs Wash, $p=0.0024 ; n=10)$. In 2 of 10 cells, 3,5DHPG induced APs (Fig. 8E,F).

Is the AP generation due to the presynaptic enhancement of sEPSPs or the postsynaptic membrane depolarization caused by activation of mGluR I, or both? To test this, we blocked synaptic 
A

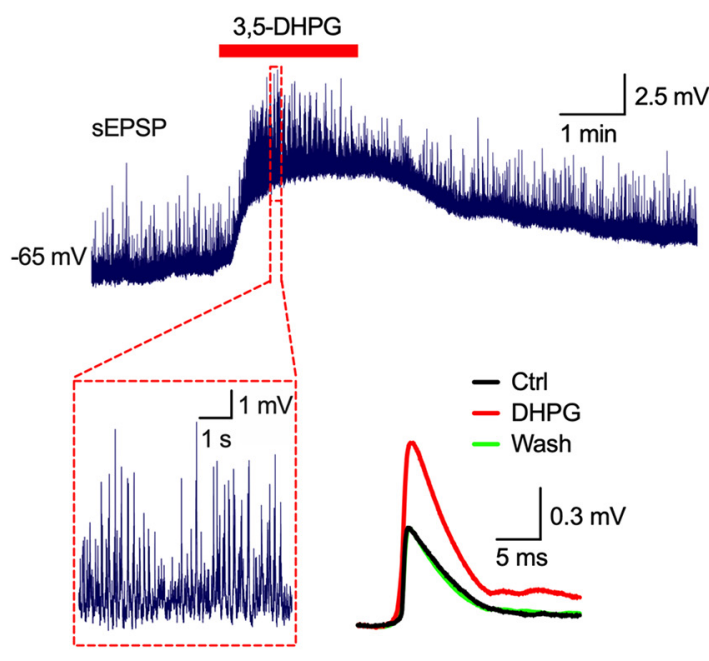

E

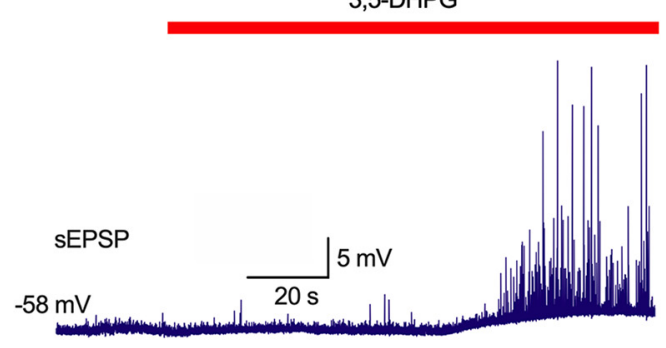

B

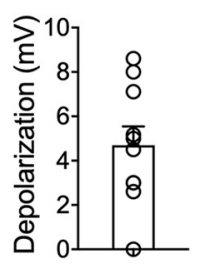

C

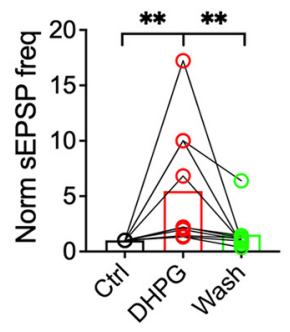

D

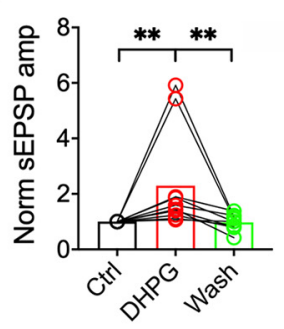

F

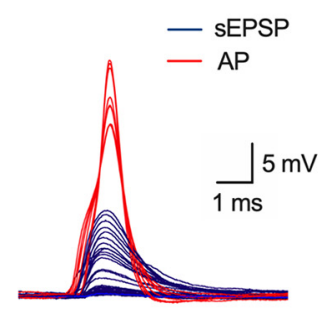

G

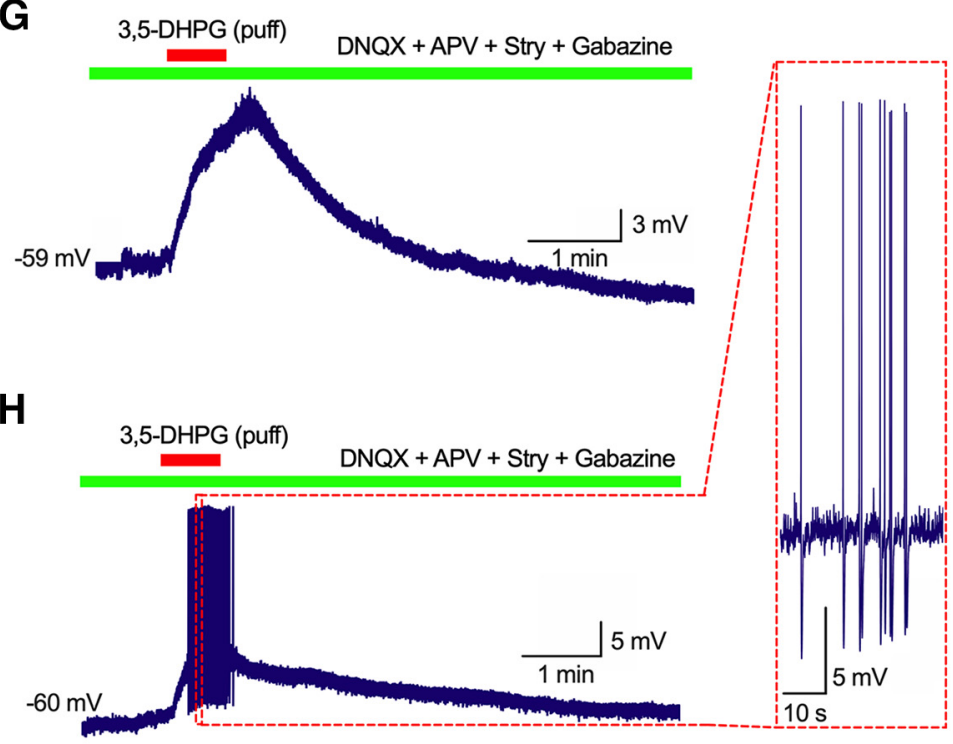

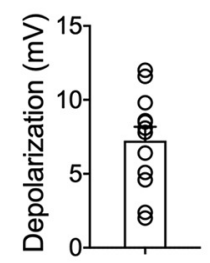

J

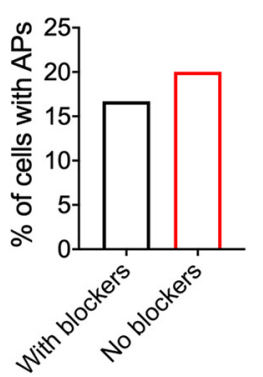

Figure 8. mGluR I affect the output of MNTB neurons. A, Top, Under current-clamp configuration, 3,5-DHPG depolarized the membrane potential, and increased the frequency and amplitude of sEPSPs in postsynaptic MNTB neurons. Bottom, A small segment of the recording during 3,5-DHPG shown at enlarged scales. Also shown on the right are the averaged sEPSPs under the three conditions. B, Depolarizations induced by 3,5-DHPG $(n=10)$. C, The frequency of sEPSPs was significantly increased by 3,5-DHPG $(n=10)$. D, The amplitude of sEPSPs was also significantly increased $(n=10)$. $\boldsymbol{E}$, In 2 of 10 cells, 3,5-DHPG induced APs (indicated by the red triangles). $\boldsymbol{F}$, The captured sEPSPs (blue) and APs (red) during 3,5-DHPG application shown at an enlarged time scale. $\boldsymbol{G}$, In the presence of a cocktail of synaptic receptor blockers, puffed 3,5-DHPG depolarized the membrane potential of MTNB neurons. $\boldsymbol{H}$, In 2 of 12 cells, APs were generated on the top of the membrane depolarization induced by 3,5-DHPG. I, Depolarizations induced by 3,5-DHPG in the presence of synaptic receptor blockers. $J$, The percentages of the tested cells that generated APs during 3,5-DHPG application with (black) or without (red) synaptic receptor blockers. 

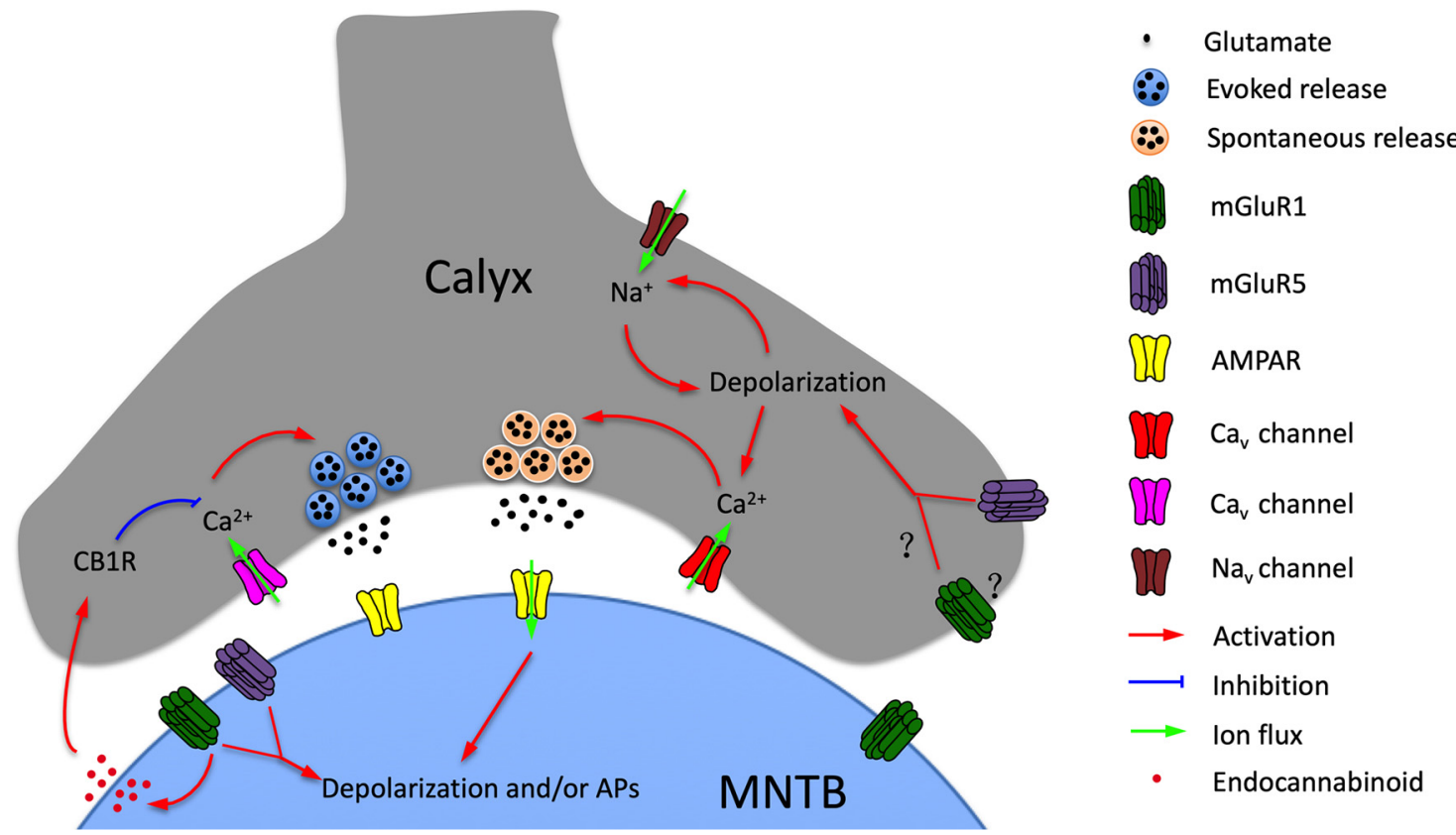

Figure 9. Hypothetical mechanisms underlying differential mGluR I modulation of eEPSC and sEPSC in MNTB. For evoked glutamatergic transmission, Kushmerick et al. (2004) demonstrated that activation of postsynaptic mGluR1 in rat MNTB neurons produces retrograde signaling molecules, which lead to the activation of CB1R1s. CB1Rs reduce evoked glutamate release potentially via inhibition of presynaptic $\mathrm{Ca}^{2+}$ current. Our current study demonstrated that for spontaneous glutamatergic transmission, presynaptic mGluR5, and likely mGluR1 to0, depolarize the membrane of calyx of Held and enhance $I_{\text {Nap. }}$. We propose that this signaling pathway targets the spontaneous glutamate vesicle pool and facilitates its release via an increase of the stochastic opening probability of presynaptic $\mathrm{Ca}_{v}$ channels that may be different from those mediating the evoked glutamate release.

transmission by applying a cocktail of synaptic receptor blockers (DNQX, $50 \mu \mathrm{M}$; APV, $50 \mu \mathrm{M}$; strychnine, $1 \mu \mathrm{M}$; gabazine, $10 \mu \mathrm{M}$ ) and then tested the effect (supposedly postsynaptic only) of 3,5DHPG. Under this condition, 3,5-DHPG $(200 \mu \mathrm{M})$ caused membrane depolarization without generating APs in 10 of 12 cells (Fig. 8G). In the other two cells, APs were observed (Fig. $8 H$ ). The average depolarization induced by $3,5-\mathrm{DHPG}$ was $7.2 \pm$ $0.9 \mathrm{mV}$ (Fig. $8 I ; n=12$ ), similar to most recently published results (5.9-7.5 $\mathrm{mV}$ depolarization depending on the age of mice; Dos Santos e Alhadas et al., 2020). The percentage of cells generating APs during 3,5-DHPG application with and without synaptic receptor blockers was about the same (Fig. 8J), suggesting that the firing due to mGluR I activation is largely a postsynaptic effect, and therefore the presynaptic effects of mGluR I activation may primarily affect synaptic integration at subthreshold levels.

\section{Discussion}

We first discovered that mGluR I exerted differential modulation on spontaneous versus evoked glutamate release in MNTB neurons. Then we investigated the mechanisms underlying the enhancement of spontaneous glutamate transmission. Local activation of the receptors at the recorded cells revealed that mGluR I at the presynaptic and postsynaptic MNTB components mediated the modulation on spontaneous glutamate release and cell depolarization, respectively. Pharmacological and anatomic data supported involvement of both mGluR1 and mGluR5, with possible functional cross talk between them. More importantly, the presynaptic modulation on spontaneous glutamate release was dependent on $\mathrm{Na}_{\mathrm{V}}$ and involved $\mathrm{Ca}_{\mathrm{V}}$ channels. The $I_{\mathrm{NaP}}$ plays a pivotal role linking mGluR I to the increased spontaneous glutamate release.

Signaling pathway underlying mGluR I enhancement of spontaneous glutamate release

Different signaling pathways underlie modulation of glutamatergic transmission by mGluR I in MNTB neurons depending on the release mode. For evoked glutamatergic transmission, activation of postsynaptic mGluR1 in MNTB neurons generates retrograde signaling molecules, diffusion of which into the calyx activates CB1Rs, which subsequently reduces eEPSCs via inhibition of presynaptic $\mathrm{Ca}^{2+}$ currents (Kushmerick et al., 2004). Here, we propose the following signaling pathway to interpret our observation that 3,5-DHPG enhanced sEPSCs in MNTB neurons (Fig. 9). First, mGluR I depolarizes the presynaptic terminal. Second, the depolarization enhances $I_{\mathrm{NaP}}$ of the calyx. Third, the stochastic opening of $\mathrm{Ca}_{\mathrm{V}}$ channels at rest is enhanced, leading to increased spontaneous glutamate release. The discussion below centers around interpretations and implications associated with each of these steps.

First, while both mGluR1 and mGluR5 were involved, why did the antagonist for each subtype nearly completely block the effect of 3,5-DHPG on sEPSCs? Although homodimers of mGluRs are the common path for each member to function, cross talk between different members has been discovered (Lee et al., 2020). Physical association and functional cooperative signaling between mGluR1 and mGluR5 have been reported (Doumazane et al., 2011; Sevastyanova and Kammermeier, 2014). We showed that mGluR5 was localized both presynaptically and postsynaptically (Fig. 4). In rats, mGluR1 is localized in the cell bodies of MNTB neurons (Kushmerick et al., 2004). Although mixed results of presynaptic mGluR1 in mice were seen (data not shown), our pharmacological results did suggest the existence of mGluR1 in the calyx. Thus, mGluR1 and mGluR5 could potentially form mGluR1-mGluR5 dimer, or interact via functional mGluR1-mGluR1 dimer with mGluR5mGluR5 dimer. Consequently, blocking either subtype would largely disable the signaling pathway, while application of both antagonists completely prevented the effect.

Second, how does the mGluR I-mediated depolarization cause enhancement of $I_{\mathrm{NaP}}$ and spontaneous glutamate release? Small in amplitude, $I_{\mathrm{NaP}}$ is functionally significant, regulating 
neuronal excitability and AP generation (Thor and Morris, 2016; Browne et al., 2017; Hsu et al., 2018; Müller et al., 2018). In hypothalamus tuberomammillary neurons, $I_{\mathrm{NaP}}$ (average, 22.6 pA) is sufficient to drive spontaneous pacemaking firing (Taddese and Bean, 2002). In cortical neurons, an increased $I_{\mathrm{NaP}}$ causes hyperexcitability by decreasing AP threshold (Deng and Klyachko, 2016). In MNTB, the presynaptic $I_{\mathrm{NaP}}$ augments the depolarizing effect of glycine and increases mEPSC frequency (Huang and Trussell, 2008). $I_{\mathrm{NaP}}$ is also highly sensitive to neuromodulation. In glutamatergic external tufted cells in the olfactory bulb, mGluR I increases $I_{\mathrm{NaP}}$ and bursting firing (Dong and Ennis, 2014). In nucleus accumbens, mGluR5 increases $I_{\mathrm{NaP}}$, enhances an afterdepolarization, and subsequently increases spike firing (D’Ascenzo et al., 2009). In our presynaptic recordings, 3,5-DHPG shifted the $V_{\text {half }}$ of $I_{\mathrm{NaP}}$ and increased the amplitude at the RMP (Fig. 6). The resulting $\mathrm{Na}^{+}$influx would further depolarize the calyx and facilitate spontaneous glutamate release. It is not uncommon that subthreshold depolarization increases spontaneous neurotransmitter release (Graydon et al., 2011; Trapani and Nicolson, 2011). In MNTB, glycine depolarizes the calyx by $8.7 \mathrm{mV}$ and increases mEPSC frequency (Turecek and Trussell, 2001). In our study, mEPSCs because of UVR were not affected by mGluR I (Fig. 5), suggesting that spontaneous MVR might be emerging because of mGluR modulation. MVR was thought to exist in only some specialized synapses, but indeed it is more common than previously believed (for review, see Rudolph et al., 2015). At the mouse calyx-MNTB synapse, MVR is likely to occur in young animals (P5) and is reduced in older animals (P12-P14; Taschenberger et al., 2002). Based on a binomial model (Oertner et al., 2002), Taschenberger et al. (2002) predicted that $\sim 14 \%$ of the successful release events in P12-P14 mouse MNTB are MVR. Such release, however, may not be AP dependent, because activation of mGluR I did not generate APs in AVCN bushy cells (Chanda and Xu-Friedman, 2011). Meanwhile, we cannot exclude AP-dependent release from noncalyceal excitatory inputs to MNTB (Hamann et al., 2003).

Third, the involvement of $\mathrm{Ca}_{V}$ channels in this mGluRinduced enhancement of sEPSCs is intriguing in that these channels usually require high membrane voltages for activation. Spontaneous transmitter release is affected by presynaptic $\mathrm{Ca}^{2+}$, and usually an increased $\mathrm{Ca}^{2+}$ concentration results in enhanced spontaneous release (for review, see Williams and Smith, 2018). The presynaptic $\mathrm{Ca}_{\mathrm{V}}$ channels have stochastic opening at RMP, and subthreshold depolarizations could enhance their opening probability and increase spontaneous release (for review, see Kavalali, 2020). Consistent with this idea, an increase in the intracellular $\mathrm{Ca}^{2+}$ concentration through the opening of $\mathrm{Ca}_{\mathrm{V}}$ channels near RMP in the calyx increased mEPSC frequency when glycine causes a presynaptic depolarization (Turecek and Trussell, 2001; Awatramani et al., 2005). A modeling study shows that a $10 \mathrm{mV}$ depolarization increases the likelihood of stochastic activation of $\mathrm{Ca}_{\mathrm{V}}$ channels and triggers $\mathrm{Ca}_{\mathrm{V}}$ channel-dependent spontaneous release (Ermolyuk et al., 2013). The R-type $\mathrm{Ca}_{\mathrm{V}}$ channels have a relatively low activation threshold and may play a prominent role in spontaneous transmitter release (Ermolyuk et al., 2013). These channels are present at the calyx (Iwasaki et al., 2000), suggesting that different $\mathrm{Ca}_{\mathrm{V}}$ channels may underlie the differential modulation of mGluR I on spontaneous versus evoked glutamate release. Additionally, while CB1R activation suppresses eEPSCs of MNTB neurons (Kushmerick et al.,
2004), sEPSCs were not affected (Fig. 7), suggesting involvement of different $\mathrm{Ca}_{\mathrm{V}}$ channels and/or different signaling pathways for spontaneous versus evoked release. Activation of mGluR I could also increase intracellular $\mathrm{Ca}^{2+}$ concentration via release of $\mathrm{Ca}^{2+}$ from internal stores (Dong et al., 2009; Pittaluga, 2016). The blockade of 3,5-DHPG effect by $\mathrm{Cd}^{2+}$ (Fig. 5) hints that the major pathway for the $\mathrm{Ca}^{2+}$ signaling may be through $\mathrm{Ca}_{\mathrm{V}}$ channels, which could induce further $\mathrm{Ca}^{2+}$ release from internal stores $\left(\mathrm{Ca}^{2+}\right.$-induced $\mathrm{Ca}^{2+}$ release). Finally, low-threshold $\mathrm{Ca}_{\mathrm{V}}$ channels could also trigger transmitter release (for review, see Carbone et al., 2014). The existence and properties of such low-threshold $\mathrm{Ca}_{\mathrm{V}}$ channels in the calyx await future investigation.

Together, activation of mGluR I generated membrane depolarization of the calyx and shifted activation voltage of $I_{\mathrm{NaP}}$ toward more hyperpolarized levels. Consequently, uncorrelated stochastic opening of $\mathrm{Ca}_{\mathrm{V}}$ channels at rest may be facilitated, causing $\mathrm{Ca}^{2+}$ influx, which may selectively target the spontaneous vesicle pool and might enhance MVR of glutamate. Meanwhile, mGluR I activation, via PKC pathway, may increase $\mathrm{Ca}^{2+}$ sensitivity of synaptic vesicle fusion (Lou et al., 2005; Vyleta and Smith, 2011). These mGluRassociated processes may work synergistically to increase spontaneous glutamate release.

\section{Functional implication}

Spontaneous and evoked neurotransmission may serve different physiological functions (for review, see Kavalali, 2015). The differential modulation of spontaneous and evoked neurotransmission by mGluRs constitutes one of the mechanisms distinguishing the functions of these two release modes. Our studies (Curry et al., 2018; and the current study) further point to potential yet unrevealed contributions of spontaneous transmitter release to neural function at the circuitry level, especially when spontaneous transmitter release is enhanced by mGluRs. Do the cellular events required for mGluR modulation of the spontaneous glutamatergic transmission at rest condition exist? The well timed excitatory input from the contralateral AVCN to MNTB is of high spiking activity. AVCN bushy cells of gerbils fire spontaneously at a rate of $\sim 50 \mathrm{~Hz}$ (Kopp-Scheinpflug et al., 2002; Keine and Rübsamen, 2015). The in vivo spontaneous firing rates of mouse $(\mathrm{CBA} / \mathrm{J})$ AVCN bushy cells vary between 22 and $62 \mathrm{~Hz}$ in P12-P18 animals (Müller et al., 2019). MNTB neurons in C57BL/6 mice fire spontaneously at $\sim 70 \mathrm{~Hz}$ in vivo (Lorteije et al., 2009), suggesting high spiking activity of the calyx. This highly active spiking status may provide the condition for spillover of glutamate and subsequent activation of mGluRs on the calyx. Following mGluR activation, spontaneous glutamate release is enhanced while evoked release is inhibited. This may constitute a mechanism critical for regulating the excitatory tone and the auditory processing at the synapse. Presynaptic enhancement of the spontaneous excitatory transmission and postsynaptic increase of excitability of MNTB neurons by mGluRs (Dos Santos e Alhadas et al., 2020; Fig. 8) may allow relatively small synaptic excitatory events transform into APs. This would minimize synaptic delays, enable fast response, and increase spike reliability. Finally, the matched modulatory direction of mGluR I on the glutamatergic and the glycinergic inputs may assist maintenance of the excitation/inhibition balance for proper circuit function and homeostasis of cellular excitability. 


\section{References}

Albrecht O, Dondzillo A, Mayer F, Thompson JA, Klug A (2014) Inhibitory projections from the ventral nucleus of the trapezoid body to the medial nucleus of the trapezoid body in the mouse. Front Neural Circuits 8:83.

Alle H, Geiger JR (2006) Combined analog and action potential coding in hippocampal mossy fibers. Science 311:1290-1293.

Awatramani GB, Turecek R, Trussell LO (2004) Inhibitory control at a synaptic relay. J Neurosci 24:2643-2647.

Awatramani GB, Price GD, Trussell LO (2005) Modulation of transmitter release by presynaptic resting potential and background calcium levels. Neuron 48:109-121.

Borst JG, Helmchen F, Sakmann B (1995) Pre-and postsynaptic whole-cell recordings in the medial nucleus of the trapezoid body of the rat. J Physiol 489:825-840.

Browne L, Smith KE, Jagger DJ (2017) Identification of persistent and resurgent sodium currents in spiral ganglion neurons cultured from the mouse cochlea. eNeuro 4:ENEURO.0303-17.2017.

Carbone E, Calorio C, Vandael DH (2014) T-type channel-mediated neurotransmitter release. Pflugers Arch 466:677-687.

Cartmell J, Schoepp DD (2000) Regulation of neurotransmitter release by metabotropic glutamate receptors. J Neurochem 75:889-907.

Chanda S, Xu-Friedman MA (2011) Excitatory modulation in the cochlear nucleus through group I metabotropic glutamate receptor activation. J Neurosci 31:7450-7455.

Crill WE (1996) Persistent sodium current in mammalian central neurons. Annu Rev Physiol 58:349-362.

Curry RJ, Peng K, Lu Y (2018) Neurotransmitter- and release-mode-specific modulation of inhibitory transmission by group I metabotropic glutamate receptors in central auditory neurons of the mouse. J Neurosci 38:8187-8199.

D’Ascenzo M, Podda MV, Fellin T, Azzena GB, Haydon P, Grassi C (2009) Activation of mGluR5 induces spike afterdepolarization and enhanced excitability in medium spiny neurons of the nucleus accumbens by modulating persistent $\mathrm{Na}+$ currents. J Physiol 587:3233-3250.

Deng PY, Klyachko VA (2016) Increased persistent sodium current causes neuronal hyperexcitability in the entorhinal cortex of Fmrl knockout mice. Cell Rep 16:3157-3166.

Dong HW, Ennis M (2014) Activation of group I metabotropic glutamate receptors enhances persistent sodium current and rhythmic bursting in main olfactory bulb external tufted cells. J Neurophysiol 111:641-647.

Dong HW, Hayar A, Callaway J, Yang XH, Nai Q, Ennis M (2009) Group I mGluR activation enhances $\mathrm{Ca}^{2+}$-dependent nonselective cation currents and rhythmic bursting in main olfactory bulb external tufted cells. J Neurosci 29:11943-11953.

Dos Santos e Alhadas E, Correa AMB, Naves LA, Kushmerick C (2020) Mechanisms and functional impact of Group I metabotropic glutamate receptor modulation of excitability in mouse MNTB neurons. Synapse 74:e22137.

Doumazane E, Scholler P, Zwier JM, Trinquet E, Rondard P, Pin JP (2011) A new approach to analyze cell surface protein complexes reveals specific heterodimeric metabotropic glutamate receptors. FASEB J 25:66-77.

Ermolyuk YS, Alder FG, Surges R, Pavlov IY, Timofeeva Y, Kullmann DM, Volynski KE (2013) Differential triggering of spontaneous glutamate release by P/Q-, N-and R-type $\mathrm{Ca}^{2+}$ channels. Nat Neurosci 16:17541763.

Fatt P, Katz B (1950) Some observations on biological noise. Nature 166:597598.

Forsythe ID (1994) Direct patch recording from identified presynaptic terminals mediating glutamatergic EPSCs in the rat CNS, in vitro. J Physiol 479:381-387.

Froemke RC (2015) Plasticity of cortical excitatory-inhibitory balance. Annu Rev Neurosci 38:195-219.

Glitsch M, Parra P, Llano I (2000) The retrograde inhibition of IPSCs in rat cerebellar Purkinje cells is highly sensitive to intracellular $\mathrm{Ca}^{2+}$. Eur J Neurosci 12:987-993.

Graydon CW, Cho S, Li GL, Kachar B, von Gersdorff H (2011) Sharp Ca ${ }^{2+}$ nanodomains beneath the ribbon promote highly synchronous multivesicular release at hair cell synapses. J Neurosci 31:16637-16650.

Grothe B, Pecka M, McAlpine D (2010) Mechanisms of sound localization in mammals. Physiol Rev 90:983-1012.
Hamann M, Billups B, Forsythe ID (2003) Non-calyceal excitatory inputs mediate low fidelity synaptic transmission in rat auditory brainstem slices. Eur J Neurosci 18:2899-2902.

Hsu CL, Zhao X, Milstein AD, Spruston N (2018) Persistent sodium current mediates the steep voltage dependence of spatial coding in hippocampal pyramidal neurons. Neuron 99:147-162.

Hu W, Bean BP (2018) Differential control of axonal and somatic resting potential by voltage-dependent conductances in cortical layer 5 pyramidal neurons. Neuron 97:1315-1326.

Huang H, Trussell LO (2008) Control of presynaptic function by a persistent $\mathrm{Na}^{+}$current. Neuron 60:975-979.

Huang H, Trussell LO (2011) KCNQ5 channels control resting properties and release probability of a synapse. Nat Neurosci 14:840-847.

Huang H, Trussell LO (2014) Presynaptic HCN channels regulate vesicular glutamate transport. Neuron 84:340-346.

Iwasaki S, Momiyama A, Uchitel OD, Takahashi T (2000) Developmental changes in calcium channel types mediating central synaptic transmission. J Neurosci 20:59-65.

Joris PX, Trussell LO (2018) The calyx of Held: a hypothesis on the need for reliable timing in an intensity-difference encoder. Neuron 100:534-549.

Kavalali ET (2015) The mechanisms and functions of spontaneous neurotransmitter release. Nat Rev Neurosci 16:5-16.

Kavalali ET (2020) Neuronal $\mathrm{Ca}^{2+}$ signalling at rest and during spontaneous neurotransmission. J Physiol 598:1649-1654.

Keine C, Rübsamen R (2015) Inhibition shapes acoustic responsiveness in spherical bushy cells. J Neurosci 35:8579-8592.

Kopp-Scheinpflug C, Dehmel S, Dörrscheidt GJ, Rübsamen R (2002) Interaction of excitation and inhibition in anteroventral cochlear nucleus neurons that receive large endbulb synaptic endings. J Neurosci 22:11004-11018.

Kushmerick C, Price GD, Taschenberger H, Puente N, Renden R, Wadiche JI, Duvoisin RM, Grandes P, von Gersdorff H (2004) Retroinhibition of presynaptic $\mathrm{Ca}^{2+}$ currents by endocannabinoids released via postsynaptic mGluR activation at a calyx synapse. J Neurosci 24:5955-5965.

Lee J, Munguba H, Gutzeit VA, Singh DR, Kristt M, Dittman JS, Levitz J (2020) Defining the homo- and heterodimerization propensities of metabotropic glutamate receptors. Cell Rep 31:107605.

Lorteije JA, Rusu SI, Kushmerick C, Borst JG (2009) Reliability and precision of the mouse calyx of Held synapse. J Neurosci 29:13770-13784.

Lou X, Scheuss V, Schneggenburger R (2005) Allosteric modulation of the presynaptic $\mathrm{Ca}^{2+}$ sensor for vesicle fusion. Nature 435:497-501.

Lu Y, Harris JA, Rubel EW (2007) Development of spontaneous miniature EPSCs in mouse AVCN neurons during a critical period of afferent-dependent neuron survival. J Neurophysiol 97:635-646.

Magnusson AK, Park TJ, Pecka M, Grothe B, Koch U (2008) Retrograde GABA signaling adjusts sound localization by balancing excitation and inhibition in the brainstem. Neuron 59:125-137.

Müller MK, Jovanovic S, Keine C, Radulovic T, Rübsamen R, Milenkovic I (2019) Functional development of principal neurons in the anteroventral cochlear nucleus extends beyond hearing onset. Front Cell Neurosci 13:119.

Müller P, Draguhn A, Egorov AV (2018) Persistent sodium current modulates axonal excitability in CA1 pyramidal neurons. J Neurochem 146:446-458.

Niswender CM, Conn PJ (2010) Metabotropic glutamate receptors: physiology, pharmacology, and disease. Annu Rev Pharmacol Toxicol 50:295322.

Oertner TG, Sabatini BL, Nimchinsky EA, Svoboda K (2002) Facilitation at single synapses probed with optical quantal analysis. Nat Neurosci 5:657664.

Pittaluga A (2016) Presynaptic release-regulating mGlul receptors in central nervous system. Front Pharmacol 7:295.

Rudolph S, Tsai M-C, von Gersdorff H, Wadiche JI (2015) The ubiquitous nature of multivesicular release. Trends Neurosci 38:428-438.

Sevastyanova TN, Kammermeier PJ (2014) Cooperative signaling between homodimers of metabotropic glutamate receptors 1 and 5. Mol Pharmacol 86:492-504.

Sierksma MC, Borst JGG (2017) Resistance to action potential depression of a rat axon terminal in vivo. Proc Natl Acad Sci U S A 114:4249-4254.

Shu Y, Hasenstaub A, Duque A, Yu Y, McCormick DA (2006) Modulation of intracortical synaptic potentials by presynaptic somatic membrane potential. Nature 441:761-765. 
Taddese A, Bean BP (2002) Subthreshold sodium current from rapidly inactivating sodium channels drives spontaneous firing of tuberomammillary neurons. Neuron 33:587-600.

Taschenberger H, Leão RM, Rowland KC, Spirou GA, von Gersdorff H (2002) Optimizing synaptic architecture and efficiency for high-frequency transmission. Neuron 36:1127-1143.

Thor MG, Morris G (2016) Contrasting roles of $I_{h}$ and the persistent sodium current at subthreshold voltages during naturalistic stimuli. J Neurophysiol 116:2001-2003.

Trapani JG, Nicolson T (2011) Mechanism of spontaneous activity in afferent neurons of the zebrafish lateral-line organ. J Neurosci 31:1614-1623.

Turecek R, Trussell LO (2001) Presynaptic glycine receptors enhance transmitter release at a mammalian central synapse. Nature 411:587-590.
Urbani A, Belluzzi O (2000) Riluzole inhibits the persistent sodium current in mammalian CNS neurons. Eur J Neurosci 12:3567-3574.

Vyleta NP, Smith SM (2011) Spontaneous glutamate release is independent of calcium influx and tonically activated by the calcium-sensing receptor. J Neurosci 31:4593-4606.

Wehr M, Zador AM (2003) Balanced inhibition underlies tuning and sharpens spike timing in auditory cortex. Nature 426:442-446.

Williams CL, Smith SM (2018) Calcium dependence of spontaneous neurotransmitter release. J Neurosci Res 96:335-347.

Xue M, Atallah BV, Scanziani M (2014) Equalizing excitation-inhibition ratios across visual cortical neurons. Nature 511:596-600.

Zhang Y, Huang H (2017) SK channels regulate resting properties and signaling reliability of a developing fast-spiking neuron. J Neurosci 37:1073810747 . 